\title{
Synthesis of solvent-free processable and on-demand cross-linkable dielectric elastomers for actuators
}

\author{
Philip Caspari, ${ }^{a, b}$ Frank A. Nüesch, ${ }^{a, b}$ and Dorina M. Opris ${ }^{a^{*}}$
}

Dielectric elastomer actuators (DEAs) have gained growing interest during the last decade both in the scientific community and industry. However, the high operating voltages needed to drive these actuators reduce their application potential. Up to date, several reports have been published on high permittivity elastomers that can be operated at low electric fields, however, little attention has been given to their processability into thin films and reliability as dielectric in actuators. This work presents the synthesis of low molecular weight polar polysiloxanes, which have a low viscosity and can, therefore, be processed into thin films by solvent-free doctor blade deposition technique. Additionally, the prepared polysiloxanes have vinyl end-groups which are subsequently used for cross-linking into thin films, whereby multifunctional thiol cross-linkers and a UV initiator are used. The prepared films are elastic and show a permittivity of about two times higher as compared to commercial polydimethylsiloxane elastomers. In addition, their elastic modulus is easily tuned between 1.2 to $0.4 \mathrm{MPa}$ using a dithiol as chain prolongation reagent, while their viscoelastic behavior is comparable to commercial silicone elastomers. When used as dielectric in DEAs the developed elastomers allow reliable operation over 180,000 actuation cycles at reduced voltages.

\section{Introduction}

Dielectric elastomer transducers (DETs) are elastic capacitors composed of a dielectric elastomer (DE) thin film placed between two compliant electrodes. ${ }^{1}$ DETs can be used as actuators (DEAs), generators (DEGs), and sensors (DESs). When the capacitor is charged, the electrostatic forces generate a mechanical pressure on the incompressible DE. As a consequence, the DEAs elongate, until the elastic and electrostatic forces are balanced and thus convert electrical energy into mechanical work. Conversely, DEGs convert mechanical work into electrical energy. ${ }^{2}$ In DESs, mechanical stress deforms the elastic capacitors and the change in capacitance can be measured. ${ }^{3}$ As of now, only few DEA devices have been industrially implemented. ${ }^{4,5}$

Poly(dimethylsiloxane) (PDMS) elastomers (silicone elastomers) are the most frequently tested DE materials ${ }^{6}$ beside natural rubber, ${ }^{7}$ acrylates, ${ }^{8}$ and polyurethanes. ${ }^{9}$ PDMS elastomers have low conductivity and their elastic modulus can be tuned by the cross-link density. Additionally, well-established cross-linking techniques allow formation of DEs with high mechanical stability. ${ }^{10}$ Therefore, PDMS outperforms alternative DE materials in response speed ${ }^{11,12}$ and lifetime, ${ }^{13}$ but not in dielectric breakdown strength, ${ }^{14}$ maximum mechanical elongation, ${ }^{15}$ and maximum actuation strain. ${ }^{1}$ While commercial polyurethane formulations can be easily processed into thin films, they tend to be water sensitive. ${ }^{16}$ Most commercial PDMS formulations use the fast and clean Pt-catalyzed hydrosilylation for crosslinking. ${ }^{17}$ Low viscosity formulations that are processable into thin films without using solvents are also available. While non-polar silicone elastomers are hydrophobic and thus less sensitive towards water uptake, they have also a low dielectric permittivity. ${ }^{18}$ Hence, high electric fields are required for the operation of PDMS-based DEAs. Equation 1 shows the relationship between the actuation strain ( $s$ ) and pressure $(p)$, which are influenced by the DE's dielectric permittivity $\left(\varepsilon^{\prime}\right)$ and elastic modulus $(Y)$ as well as by the applied electric field $(U / d)^{1}$

$$
S_{Z}=\frac{p}{Y}=\frac{\varepsilon \varepsilon_{0}\left(\frac{U}{d}\right)^{2}}{Y}
$$

The high operating voltage is the main disadvantage of PDMS-based DEAs compared to ionic EAPs ${ }^{19,20}$ or piezoelectric devices. ${ }^{21} \mathrm{High}$ voltage operation raises questions regarding safety when such devices are used in direct contact to humans. ${ }^{22}$ Furthermore, the need for high voltage converters complicates the construction of the devices and increases costs.

Therefore, over the last decade manifold research activities have been initiated to lower the driving voltage of DEAs by reducing the elastic modulus ${ }^{23-25}$ and film thickness ${ }^{26,27}$ as well as by increasing the permittivity of the DE. ${ }^{6}$ A low elastic modulus of the DE leads not only to a decrease in the driving voltage but also to a decreased output pressure. In addition, a simultaneous reduction of dielectric breakdown strength $\left(E_{\max }\right)$ might pose challenges with respect to reliability and lifetime of the device. ${ }^{28}$ Thinning down the DE film can be a very promising approach, particularly in combination with multi-layer devices. ${ }^{29}$ However, there is also a limit as low-cost processing of ultra-thin high-quality elastomers might be rather challenging. Therefore, the relative permittivity, as an intrinsic material parameter is of high interest for low-voltage DEA applications.

High dielectric permittivity additives such as $\mathrm{BaTiO}_{3},{ }^{30} \mathrm{~Pb}\left(\mathrm{Mg}_{1 / 3} \mathrm{Nb}_{2 / 3}\right) \mathrm{O}_{3} / \mathrm{PbTiO}_{3},{ }^{31}$ glycerol, ${ }^{32}$ and $\mathrm{TiO}_{2},{ }^{33}$ polyaniline, ${ }^{34}$ polythiophene ${ }^{35}$ were mixed with PDMS and cross-linked. Some of the composites showed a remarkable rise in permittivity, however, reliability and lifetime tests have been only rarely reported. ${ }^{34}$ Additionally, the processability of silicone composites into thin films requires solvents to reduce composite viscosity, which increases fabrication costs, is environmentally unfriendly, may introduce defect into films, and is not compatible with a layer-by-layer deposition needed for stacking actuators. 
Chemical modification of polysiloxanes with organic dipoles is an alternative to high dielectric permittivity additives. ${ }^{6}$ The incorporation of organic dipoles into the polysiloxane network has been either realized by using polar cross-linkers or by cross-linking polysiloxanes that carry polar side groups. ${ }^{36-42}$ A drastic increase in permittivity of up to 18 was reported for a nitrile modified silicone elastomer which gave a lateral actuation strain of $10 \%$ at $10 \mathrm{~V} / \mu \mathrm{m} .{ }^{42,43}$ However, often the polar groups on polysiloxanes interfere with the well-established siloxane cross-linking reactions. Additionally, for thin film formation, a solvent has to be used to reduce the viscosity of the polymers. ${ }^{44}$ Consequently, to the best of our knowledge, only two examples of solvent-free Pt-catalyzed thin-film processing of polar silicones have been reported. ${ }^{38,41}$ In both cases chloroalkyl polysiloxane side groups were integrated into the elastomeric network. However, it has remained unclear to what extent the chloroalkyl moiety influences the cross-linking process with respect to conversion and reaction rate. An overall film formation time of about $30 \mathrm{~min}$ was reported, which is rather high if large scale production of stacked actuators is envisioned. ${ }^{38}$ Furthermore, the performance and the lifetime of those polar silicone elastomers have not been tested in DEAs up to date.

We have recently reported the preparation of ethyl thioeter modified thin film silicone elastomers using a Sn-catalyzed condensation reaction for cross-linking. ${ }^{45}$ Even though the obtained elastomers showed promising performance in DEAs, their processing into thin films required solvent and prolonged cross-linking time. In this work, we present a novel synthetic approach to ethyl thioeter polysiloxanes that have either allyl or vinyl end-groups, which can be processed into thin films without using solvents and subsequently cross-linked by UVinduced thiol-ene reaction within 10 minutes. We do not only describe the challenges faced during thin film processability and the electromechanical performance, but also address the limitations and remaining challenges with respect to conductivity and lifetime of the polar silicone elastomers in DEA devices, thus bridging the gap between a purely academic synthetic approach and a technologically relevant material.

\section{Experimental Section}

\subsection{Materials}

Unless otherwise stated, all chemicals were reagent grade and used without purification. Poly(ethyl-2-thioethyl)(methyl)siloxane was synthesized according to literature. ${ }^{42}$ Except of the cross-linking reaction, all chemical manipulations were carried out under argon atmosphere. 1,3,5,7-Tetramethyl-1,3,5,7-tetravinyl cyclotetrasiloxane (V4), 1,3-bis(3-aminopropyl)tetramethyldisiloxane,1,3bis(vinyldimethyl)disiloxane, silanol terminated PDMS (OH-PDMS) (AB116665 $\left(M_{n}=139 \mathrm{kDa}\right), A B 109358\left(M_{n}=28 \mathrm{kDa}\right), A B 109360\left(M_{n}=63\right.$ $\mathrm{kDa})$ ) and poly(3-mercaptopropyl)(methyl)siloxane ( $A B$ 113729) were purchased from $A B C R . \quad 2,2^{\prime}$-(ethylene-dioxy)diethanethiol $\mathbf{R}_{\mathbf{1}}(\mathbf{S H})_{\mathbf{2}}$, allyl isocyanate, concentrated $\mathrm{H}_{2} \mathrm{SO}_{4}(96 \%)$, 2,2-dimethoxy-2-phenylacetophenone (DMPA), ethanethiol, tetramethylammonium hydroxide $25 \%$ in $\mathrm{H}_{2} \mathrm{O}$ (TMAH), activated charcoal, and DuraSeal ${ }^{\mathrm{TM}}$ laboratory stretch film were purchased from Aldrich. Tetrahydrofuran (THF) was purchased from VWR. Films of Elastosil ${ }^{\circledR}$ Film $(200 \mu \mathrm{m}, 100 \mu \mathrm{m}, 50 \mu \mathrm{m}, 20 \mu \mathrm{m})$ were provided by DRAWIN Vertriebs-GmbH, Riemerling. Polyvinylalcohol (PVA) was purchased from Swiss Composite.

\subsection{Characterization}

${ }^{1} \mathrm{H}$ and ${ }^{13} \mathrm{C}$ NMR spectra were recorded at $298 \mathrm{~K}$ on a Bruker Avance 400NMR spectrometer using a $5 \mathrm{~mm}$ broadband inverse probe at 400.13 and $100.61 \mathrm{MHz}$, respectively. Chemical shifts $(\delta)$ in ppm were calibrated to residual solvent peaks $\left(\mathrm{CDCl}_{3}: \delta=7.26\right.$ and $\left.77.16 \mathrm{ppm}\right)$.

Gel permeation chromatograms were recorded using an Agilent 1100 Series HPLC (Columns: serial coupled PSS SDV $5 \mathrm{~m}, 100 \AA$ and PSS SDV $5 \mathrm{~m}, 1000 \AA$, detector: DAD, $235 \mathrm{~nm}$ and $360 \mathrm{~nm}$; refractive index), with THF as mobile phase. PDMS standards were used for calibration and toluene as an internal standard.

Differential scanning calorimetry (DSC) investigations were undertaken on a Pyris Diamond DSC (Perkin Elmer USA) instrument under nitrogen flow $\left(50 \mathrm{ml} \times \mathrm{min}^{-1}\right)$, in aluminum crucibles shut with pierced lids and using about $10 \mathrm{mg}$ sample mass.

The viscosity $\eta$ was measured between $1-10 \mathrm{~Hz}$ on the ARES Rheometer from TA instruments with a parallel plate setup (50 mm plate diameter, $1 \mathrm{~mm}$ plate distance) at $24^{\circ} \mathrm{C}$.

The tensile tests were performed on a Zwick 2010 tensile test machine with a crosshead speed of $50 \mathrm{~mm} \mathrm{~min}^{-1}\left(278 \% \mathrm{~min}^{-1}\right)$. Tensile test specimens with a gauge width of $2 \mathrm{~mm}$ and a gauge length of $18 \mathrm{~mm}$ were prepared by die-cutting. The strain was determined using a longitudinal strain extensometer. The curves were averaged from 3 different samples. The elastic modulus $Y$ was determined from the slope of the stress-strain curves using a linear fit to the data points within $\pm 5 \%$ strain. Thermal gravimetric analysis (TGA) was conducted on a Netzsch TG 209 F1 in synthetic air $\left(20 \% \mathrm{O}_{2}, 80 \% \mathrm{~N}_{2}\right)$.

Dynamic mechanical analysis was carried out on a RSA 3 DMA from TA Instruments. Stripes of $10 \mathrm{~mm} \times 20 \mathrm{~mm}$ were measured under a dynamic load of $2 \mathrm{~g}$, at $2 \%$ strain in the frequency range of $0.05-2.05 \mathrm{~Hz}$ at $25^{\circ} \mathrm{C}$. The mechanical loss factor $\tan (\delta)$ is given as the fraction of imaginary and real storage modulus at $2 \%$ strain.

Permittivity measurements were performed in the frequency range from $10^{-1} \mathrm{~Hz}$ to $10^{6} \mathrm{~Hz}$ using a Novocontrol Alpha-A frequency analyzer. The VRMS (root mean square voltage) of the probing AC electric signal applied to the samples was $1 \mathrm{~V}$. The permittivity $\varepsilon^{\prime}$ was determined from the capacitance $\mathrm{C}=\varepsilon^{\prime} \varepsilon_{0} \mathrm{~A} / \mathrm{d}$, where $A$ is the electrode area, $d$ is the thickness of the film, and $\varepsilon_{0}$ is the vacuum permittivity. The thickness of the film was measured by a micrometer gauge with an uncertainty of $\pm 5 \mu \mathrm{m}$. Two stainless steel discs with a diameter of $20 \mathrm{~mm}$ served as electrodes which were either placed on the films or were separated by three glass fibers with a diameter of $100 \mu \mathrm{m} \pm 5$ $\mu \mathrm{m}$ for the liquid samples. Before measurement, the samples were annealed at $80^{\circ} \mathrm{C}$ for $18 \mathrm{~h}$ at $10 \mathrm{mbar}$.

Electromechanical tests were performed using circular membrane actuators at ambient temperature and humidity. The silicone thin films on a PVA substrate were fixed between two circular frames immersed in $\mathrm{H}_{2} \mathrm{O}$ subsequent to drying at $80{ }^{\circ} \mathrm{C}$ in vacuo for $48 \mathrm{~h}$ and drying at air for $48 \mathrm{~h}$. Circular electrodes ( $8 \mathrm{~mm}$ diameter) of carbon black powder were applied to each side of the film. A FUG HCL- 3512,500 high voltage source served as a power supply for actuator tests. The voltage was increased by $50 \mathrm{~V}$ steps every $2 \mathrm{~s}$ up to maximum $5.6 \mathrm{kV}$. The actuation strain was measured optically as the extension of the diameter of the electrode area via a digital camera, using an edge detection tool of a LabView program to detect the boundary between the black electrode area and the transparent silicone film. The maximum resolution of LabView was 30 measurements per second. Current leakage was measured up to a voltage of $5 \mathrm{kV}$. 


\subsection{Synthesis of $\mathrm{P} 1\left(M_{n}=2500 \mathrm{~g} / \mathrm{mol}\right)$}

A $25 \mathrm{wt} \%$ aqueous solution of tetramethylammonium hydroxide $(0.1 \mathrm{ml}, 0.0003 \mathrm{~mol}, 0.01$ eq.) was added to a $250 \mathrm{ml}$ Schlenk flask. All

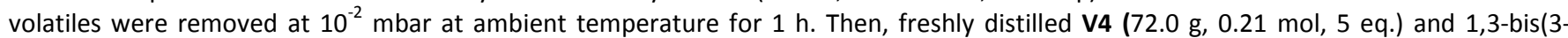
aminopropyl)tetramethyldisiloxane $\left(11.0 \mathrm{ml}, 0.04 \mathrm{~mol}, 1\right.$ eq.) were added. The reaction mixture was warmed up to $75{ }^{\circ} \mathrm{C}$ and stirred overnight. The reaction temperature was increased to $145^{\circ} \mathrm{C}$ at $100 \mathrm{mbar}$ for $4 \mathrm{~h}$. Finally, all volatiles were removed at $150{ }^{\circ} \mathrm{C}$ at $10^{-2} \mathrm{mbar}$ to yield $72.2 \mathrm{~g}(88 \%)$ of $\mathbf{P 1}$ as colourless liquid. ${ }^{1} \mathrm{H}$ NMR $\left(400 \mathrm{MHz}, \mathrm{CDCl}_{3}\right) \delta, \mathrm{ppm}: 6.03-5.75\left(\mathrm{~m}, 82 \mathrm{H}, \mathrm{Si}-\mathrm{CH}_{2}=\mathrm{CH}_{2}\right), 2.66\left(\mathrm{t},{ }^{3} \mathrm{~J}=7.0 \mathrm{~Hz}, 4 \mathrm{H},-\right.$ $\left.\mathrm{CH}_{2}-\underline{\mathrm{C}}_{2}-\mathrm{NH}_{2}\right), 1.91$ (br s, 4H, $\left.-\mathrm{CH}_{2}-\mathrm{N}_{2}\right), 1.49-1.41\left(\mathrm{~m}, 4 \mathrm{H},-\mathrm{CH}_{2}-\mathrm{C}_{2}-\mathrm{CH}_{2}-\right), 0.56-0.51\left(\mathrm{~m}, 4 \mathrm{H},-\mathrm{Si}-\mathrm{C}_{2}-\mathrm{CH}_{2}-\right), 0.14\left(\mathrm{br} \mathrm{s}, 82 \mathrm{H},-\mathrm{Si}-\mathrm{CH}_{3}\right), 0.08(\mathrm{br}$ $\left.\mathrm{s}, 16 \mathrm{H},-\mathrm{Si}-\left(\mathrm{C}_{3}\right)_{2}-\mathrm{CH}_{2}-\right) .{ }^{13} \mathrm{C} \mathrm{NMR}\left(100 \mathrm{MHz}, \mathrm{CDCl}_{3}\right) \delta$, ppm: 137.07, 133.45, 1.385, 0.5168, $-0.2274 . \mathrm{M}_{n}=2500 \mathrm{~g} / \mathrm{mol}$ by ${ }^{1} \mathrm{H} \mathrm{NMR}$. The molar mass could not be determined by GPC because $\mathbf{P} \mathbf{1}$ interacts with the column.

\subsection{Synthesis of $P 1\left(M_{n}=5500 \mathrm{~g} / \mathrm{mol}\right)$}

A $25 \mathrm{wt} \%$ aqueous solution of tetramethylammonium hydroxide $(0.02 \mathrm{ml}, 0.05 \mathrm{mmol}, 0.003 \mathrm{eq}$.) was added to a $250 \mathrm{ml}$ Schlenk flask. All volatiles were removed at $10^{-2} \mathrm{mbar}$ at ambient temperature for $1 \mathrm{~h}$. Then, freshly distilled $\mathbf{V} \mathbf{4}(30 \mathrm{~g}, 0.09 \mathrm{~mol}, 11 \mathrm{eq}$.) and 1,3-bis(3aminopropyl)tetramethyldisiloxane $\left(2.3 \mathrm{ml}, 0.008 \mathrm{~mol}, 1\right.$ eq.) were added. The reaction mixture was warmed up to $75{ }^{\circ} \mathrm{C}$ and stirred overnight. The reaction temperature was increased to $145^{\circ} \mathrm{C}$ at $100 \mathrm{mbar}$ for $4 \mathrm{~h}$. Finally, all volatiles were removed at $150{ }^{\circ} \mathrm{C}$ at $10^{-2} \mathrm{mbar}$ to yield 26. $\mathrm{g}(83 \%)$ of $\mathbf{P 1 . 1}$ as colourless liquid. ${ }^{1} \mathrm{H}$ NMR $(400 \mathrm{MHz}, \mathrm{CDCl})_{3} \delta, \mathrm{ppm}: 6.03-5.75\left(\mathrm{~m}, 190 \mathrm{H}, \mathrm{Si}-\mathrm{CH}_{2}=\mathrm{CH}_{2}\right), 2.66\left(\mathrm{t},{ }^{3} \mathrm{~J}=7.0 \mathrm{~Hz}, 4 \mathrm{H},-\right.$ $\left.\mathrm{CH}_{2}-\mathrm{CH}_{2}-\mathrm{NH}_{2}\right), 1.91$ (br s, $\left.4 \mathrm{H},-\mathrm{CH}_{2}-\mathrm{NH}_{2}\right), 1.49-1.41\left(\mathrm{~m}, 4 \mathrm{H},-\mathrm{CH}_{2}-\mathrm{CH}_{2}-\mathrm{CH}_{2}-\right), 0.56-0.51\left(\mathrm{~m}, 4 \mathrm{H},-\mathrm{Si}_{-}-\underline{H}_{2}-\mathrm{CH}_{2}-\right), 0.14\left(\mathrm{br} \mathrm{s}, 192 \mathrm{H},-\mathrm{Si}-\mathrm{CH}_{3}\right) .{ }^{13} \mathrm{C}$ NMR $\left(100 \mathrm{MHz}_{1} \mathrm{CDCl}_{3}\right) \delta$, ppm: 136.99, 133.39, $-0.39 . \mathrm{M}_{n}=5500 \mathrm{~g} / \mathrm{mol}$ by ${ }^{1} \mathrm{H}$ NMR. The molar mass could not be determined by GPC because $\mathbf{P 1}$ interacts with the column.

\subsection{Synthesis of $P 2$ and $P 3$}

P1 (43 g, 0.5 mol repeat units, 1 eq.) was added to a solution of ethanethiol ( $200 \mathrm{ml}, 2.7 \mathrm{~mol}, 5.4$ eq.) and DMPA (1.3 g, $0.005 \mathrm{~mol}, 0.01 \mathrm{eq}$ ) in THF $(600 \mathrm{ml})$ in a 1l-Schlenk-flask. The mixture was cooled down to $0{ }^{\circ} \mathrm{C}$ by an ice bath and irradiated for 3 min with a UV light. Afterward, all volatiles were removed at $10 \mathrm{mbar}$ at ambient temperature. $\mathbf{P 2}$ was obtained as yellowish liquid. Allyl isocyanate (10 $\mathrm{ml}, 0.11$ mol, 0.22 eq.) was added to $\mathbf{P 2}$ and the reaction mixture was stirred at ambient temperature overnight. Afterward, all volatiles were removed at $10^{-2} \mathrm{mbar}$ and $120^{\circ} \mathrm{C}$. The residue was dissolved in THF and filtered (PTFE syringe filter, pore size $0.2 \mu \mathrm{m}$ ). Finally, all volatiles were removed at $10^{-2} \mathrm{mbar}$ and $120^{\circ} \mathrm{C}$ overnight. P3 (65 g, 85\%) was obtained as slightly yellowish liquid.

${ }^{1} \mathrm{H}$ NMR $\left(400 \mathrm{MHz}, \mathrm{CDCl}_{3}\right) \delta$, ppm: 5.90-5.80 (m, 2H, $\left.-\mathrm{C}_{\underline{H}}=\mathrm{CH}_{2}\right), 5.21-5.09\left(\mathrm{~m}, 4 \mathrm{H},-\mathrm{CH}=\mathrm{C}_{2}\right), 3.81-3.79\left(\mathrm{~m}, 4 \mathrm{H},-\mathrm{CH}=\mathrm{CH}_{2}\right), 3.18-3.14(\mathrm{~m}$, $\left.4 \mathrm{H},-\underline{\mathrm{C}}_{2}-\mathrm{CH}=\mathrm{CH}_{2}\right), 2.58-2.52\left(\mathrm{~m}, 84 \mathrm{H},-\mathrm{CH}_{2}-\mathrm{S}-\mathrm{CH}_{2}-\right), 1.24\left(\mathrm{t},{ }^{3} \mathrm{~J}=7.4 \mathrm{~Hz}, 70 \mathrm{H},-\mathrm{CH}_{2}-\mathrm{C}_{3}\right), 0.91-0.87\left(\mathrm{~m}, 41 \mathrm{H}, \mathrm{Si}-\mathrm{C}_{2}-\mathrm{CH}_{2}-\right), 0.14(\mathrm{br} \mathrm{s}, 62 \mathrm{H}, \mathrm{Si}-$ $\left.\mathrm{CH}_{3}\right), 0.09$ (br s, $\left.15 \mathrm{H},-\mathrm{Si}-\left(\mathrm{CH}_{3}\right)_{2}\right) .{ }^{13} \mathrm{C}$ NMR $\left(100 \mathrm{MHz}_{1} \mathrm{CDCl}_{3}\right) \delta, \mathrm{ppm}: 43.63,26.20,26.09,18.59,16.21,15.64,15.038,14.85,1.37,0.58,0.29$. The number average molar mass of P3 by ${ }^{1} \mathrm{H}$ NMR $M_{n}=3500 \mathrm{~g} / \mathrm{mol}$. GPC of P3: $M_{n}=3000 \mathrm{~g} / \mathrm{mol}, M_{w}=7000 \mathrm{~g} / \mathrm{mol}, P D I=2.4$.

\subsection{Synthesis of P5}

High molecular weight poly(ethyl-2-thioethyl)(methyl)siloxane ${ }^{45}(5 \mathrm{~g}, 0.03 \mathrm{mmol}, 1$ eq.) and 1,3-bis(vinyldimethyl)disiloxane (5 g, $28 \mathrm{mmol}$, 930 eq.) were mixed in a $50 \mathrm{ml}$ Schlenk-flask at ambient temperature. Concentrated sulfuric acid (96\%) $(0.010 \mathrm{~g}, 0.1 \mathrm{mmol}, 3 \mathrm{eq}$.) was added and the mixture was stirred overnight at ambient temperatures. All volatiles were removed at $130{ }^{\circ} \mathrm{C}$ in vacuo $\left(10^{-2} \mathrm{mbar}\right)$ for $1 \mathrm{~h}$. The residue was dissolved in THF $(20 \mathrm{ml})$ and activated charcoal $(2 \mathrm{~g})$ was added. The suspension was filtered and all volatiles were removed at $130{ }^{\circ} \mathrm{C}$ at $10^{-2} \mathrm{mbar}$ for $1 \mathrm{~h}$. $\mathbf{P 5}(3.9 \mathrm{~g}, 76 \%)$ was obtained as pale yellowish liquid. $\left.{ }^{1} \mathrm{H} \mathrm{NMR}(400 \mathrm{MHz}, \mathrm{CDCl})_{3}\right) \delta, \mathrm{ppm}: 6.16-5.70$ $\left(\mathrm{m}, 6 \mathrm{H},-\mathrm{CH}=\mathrm{CH}_{2}\right), 2.58-2.50\left(\mathrm{~m}, 173 \mathrm{H},-\mathrm{CH}_{2}-\mathrm{S}-\mathrm{CH}_{2}-\right), 1.242\left(\mathrm{t},{ }^{3} \mathrm{~J}=7.3 \mathrm{~Hz}, 142 \mathrm{H},-\mathrm{CH}_{2}-\mathrm{CH}_{3}\right), 0.91-0.87\left(\mathrm{~m}, 85 \mathrm{H}, \mathrm{Si}-\mathrm{CH}_{2}-\mathrm{CH}_{2}-\right), 0.15(\mathrm{br} \mathrm{s}, 147 \mathrm{H}$, $\left.\mathrm{Si}-\mathrm{CH}_{3}\right) .{ }^{13} \mathrm{C} N M R\left(100 \mathrm{MHz}, \mathrm{CDCl}_{3}\right) \delta$, ppm: 26.15, 26.02, 18.52, 18.24, 18.05, 14.95, 0.23, -0.23 . The number average molar mass of P5 by ${ }^{1} \mathrm{H}$ NMR $M_{n}=7000 \mathrm{~g} / \mathrm{mol}$. By GPC: $M_{n}=8500 \mathrm{~g} / \mathrm{mol}, M_{w}=20000 \mathrm{~g} / \mathrm{mol}, \mathrm{PDI}=2.4$.

\subsection{Synthesis of $\mathrm{R}(\mathrm{SH})_{3}$}

Freshly distilled V4 $(5.0 \mathrm{~g}, 0.015 \mathrm{~mol}, 1$ eq.), 2,2'-(ethylene-dioxy)diethanethiol $(80.0 \mathrm{ml}, 0.5 \mathrm{~mol}, 33 \mathrm{eq}$ ) and DMPA (0.08 g, $0.3 \mathrm{mmol}, 0.02$ eq.) were dissolved in THF $(150 \mathrm{ml})$. The reaction mixture was cooled down to $0^{\circ} \mathrm{C}$ and irradiated for 3 min with a UV light. Afterwards, all volatiles were removed at $100 \mathrm{mbar} / 80{ }^{\circ} \mathrm{C}$ and at $10^{-2} \mathrm{mbar} / 135^{\circ} \mathrm{C}$ overnight. $\mathbf{R}(\mathrm{SH})_{3}(13.7 \mathrm{~g}, 88 \%)$ was obtained as colourless liquid. ${ }^{1} \mathrm{H}$ NMR (400 MHz, CDCl$) \delta, ~ p p m: ~ 3.66-3.60 ~\left(m, ~ 8 H, ~ C \underline{H}_{2}-\mathrm{O}-\left(\mathrm{C}_{2}\right)_{2}-\mathrm{O}-\mathrm{C}_{2}\right)$, 2.74-2.67 (m, 4H, S- $\left.\mathrm{C}_{2}-\mathrm{CH}_{2}-\mathrm{O}, \mathrm{C}_{2}-\mathrm{SH}\right), 2.61-2.57\left(\mathrm{~m}, 2 \mathrm{H}, \mathrm{Si}-\mathrm{CH}{ }_{2}-\right.$ $\left.\left.\mathrm{C}_{2}-{ }_{2}\right), 1.58\left(\mathrm{t},{ }^{3} \mathrm{~J}=8.3 \mathrm{~Hz}, 4 \mathrm{H},-\mathrm{CH}_{2}-\mathrm{CH}_{2}-\mathrm{NH}_{2}\right), 0.94-0.88\left(\mathrm{~m}, 2 \mathrm{H}, \mathrm{Si}-\mathrm{C}_{2}-\mathrm{CH}_{2}-\right), 0.12\left(\mathrm{~m}, 3 \mathrm{H}, \mathrm{Si}_{-}-\underline{\mathrm{H}}_{3}\right) .{ }^{13} \mathrm{C} \mathrm{NMR}(100 \mathrm{MHz}, \mathrm{CDCl})_{3}\right) \delta, \mathrm{ppm}: 73.34$, $71.27,70.68,31.77,27.28,24.68,18.36,1.42,0.00$. GPC elution curves of $\mathbf{R}(\mathbf{S H})_{3}$ are shown in Supporting Information.

\subsection{General synthesis of E3-Y and E5}

P3/P5 was mixed with DMPA, cross-linker $\mathbf{R}(\mathbf{S H})_{3} / \mathrm{AB}_{113729}$ and chain-prologation reagent $\mathbf{R}_{\mathbf{1}}(\mathbf{S H})_{\mathbf{2}}$ (for the amount used, see Table 1 ) and sonicated for $10 \mathrm{~min}$ at $70^{\circ} \mathrm{C}$. The reaction mixture was directly cast by doctor blade technique (blade thickness adjusted to $100 \mu \mathrm{m}$ ) on a PVA/glass substrate. The substrate was placed on a heating plate at $80{ }^{\circ} \mathrm{C}$ for $5 \mathrm{~min}$ subsequent to UV-irradiation of $3 \mathrm{~min}$ at ambient temperature. The silicone elastomer with the PVA layer was removed from the glass substrate and placed with the top surface on DuraSeal ${ }^{\mathrm{TM}}$ laboratory stretch film. The PVA was dissolved in $\mathrm{H}_{2} \mathrm{O}$ and the silicone elastomer thin film was dried in vacuum for $12 \mathrm{~h}$ at $80{ }^{\circ} \mathrm{C}$. 
Table 1 The reagents and amounts used for the synthesis of E3-Y ${ }^{\mathrm{a}}$ and E5.

\begin{tabular}{llllll}
\hline Entry & Elastomer & $\begin{array}{l}\mathbf{P 3}^{\mathrm{b}} \text { or }_{\mathbf{P 5}}{ }^{\mathrm{C}} \\
{[\mathrm{g}] /[\mathrm{mol}]}\end{array}$ & $\begin{array}{l}\mathbf{R}(\mathbf{S H})_{3}{ }^{\mathrm{d}} \\
{[\mathrm{g}] /[\mathrm{mol}]}\end{array}$ & $\begin{array}{l}\mathbf{R}^{1}(\mathbf{S H})_{2}{ }^{\mathrm{e}} \\
{[\mathrm{g}] /[\mathrm{mol}]}\end{array}$ & $\begin{array}{l}\mathbf{D M P A}^{{ }^{f}} \\
{[\mathrm{~g}] /[\mathrm{mol}]}\end{array}$ \\
\hline $\mathbf{1}$ & $\mathbf{E 3 - 1}$ & $1.5 / 4.3 \times 10^{-4}$ & $0.276 / 2.6 \times 10^{-4}$ & - & $0.03 / 1.0 \times 10^{-4}$ \\
$\mathbf{2}$ & E3-2 & $1.5 / 4.3 \times 10^{-4}$ & $0.165 / 1.5 \times 10^{-4}$ & $0.030 / 1.6 \times 10^{-4}$ & $0.03 / 1.0 \times 10^{-4}$ \\
$\mathbf{3}$ & E3-3 & $1.5 / 4.3 \times 10^{-4}$ & $0.108 / 1.0 \times 10^{-4}$ & $0.045 / 2.5 \times 10^{-4}$ & $0.03 / 1.0 \times 10^{-4}$ \\
$\mathbf{4}$ & E3-4 & $1.5 / 4.3 \times 10^{-4}$ & $0.090 / 0.8 \times 10^{-4}$ & $0.060 / 3.3 \times 10^{-4}$ & $0.03 / 1.0 \times 10^{-4}$ \\
$\mathbf{5}$ & E5 & $1.5 / 1.9 \times 10^{-4}$ & ${ }^{\mathrm{g}_{0}} 0.045 / 3.4 \times 10^{-4}$ & - & $0.03 / 1.0 \times 10^{-4}$ \\
\hline
\end{tabular}

${ }^{\mathrm{a}} \mathbf{E} 3$ indicates that the reaction products are elastomers made of $\mathbf{P 3}$ and $\mathbf{Y}$ refers to entry in Table $2 ;{ }^{\mathrm{b}} M_{n}=3500 \mathrm{~g} / \mathrm{mol} ;{ }^{\mathrm{C}} M_{n}=7000 \mathrm{~g} / \mathrm{mol}$; ${ }^{\mathrm{d}} M_{n}=1072 \mathrm{~g} / \mathrm{mol}\left(\mathbf{R}(\mathrm{SH})_{3}\right) ;{ }^{\mathrm{e}} M_{n}=182 \mathrm{~g} / \mathrm{mol} .{ }^{\mathrm{f}} M_{n}=256 \mathrm{~g} / \mathrm{mol} .{ }^{. \mathrm{g}} \mathrm{AB} 113729$ was used for cross-linking $M_{n}=134 \mathrm{~g} / \mathrm{mol}$ (repeat unit).

\section{Results and discussion}

\subsection{Synthesis of polar oligosiloxanes}

To achieve silicone elastomers with increased dielectric permittivity via a solvent-free process, polar polysiloxanes with low viscosity and thus rather low molar mass have to be used. However, such polymers when cross-linked give access to networks with rather high crosslinking density, which tend to be stiff. To decrease the cross-linking density, a chain prolongation reaction, which occurs after the silicone formulation is processed into thin films, has to be used. First, good access to polysiloxanes with defined end-groups which can be subsequently used for chain prolongation and cross-linking has to be achieved. Scheme 1a describes the synthetic approach to ethyl thioether modified polysiloxane P3 and P5 which carries allyl and vinyl end-groups, respectively. The end-groups will be subsequently used for cross-linking or for both, chain prolongation and cross-linking into thin films. The ring-opening polymerization of 2,4,6,8-tetramethyl2,4,6,8-tetravinylcyclotetrasiloxane (V4) by tetramethylammoniumhydroxide (TMAH) in presence of 1,3-bis(3aminopropyl)tetramethyldisiloxane end-blocker gave polymer P1, which carries a vinyl group at every siloxy unit and aminopropyl endgroups. The molecular weight of P1 can be controlled by the amount of end-blocker used. Two different batches of P1 were prepared for which the number average molar masses were determined by ${ }^{1} \mathrm{H}$ NMR using the integrals of the signals of the end-groups and of the sidegroups while assuming there were no cyclic compounds and all end-groups were aminopropyl (Fig. S1, S2). For the two batches, depending on the amount of end-blocker used, the number average molar masses were $M_{n}=2.5 \mathrm{kDa}$ and $M_{n}=5.8 \mathrm{kDa}$, respectively.

a)

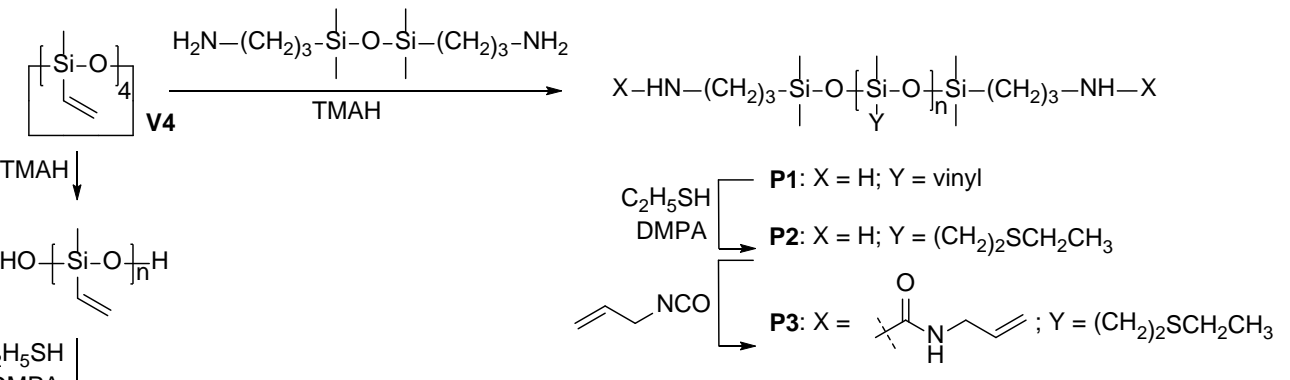

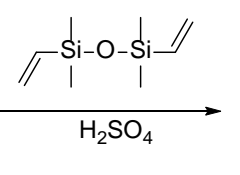

P4

DMPA<smiles>[R9]CCS(C)(C)O</smiles>

b)

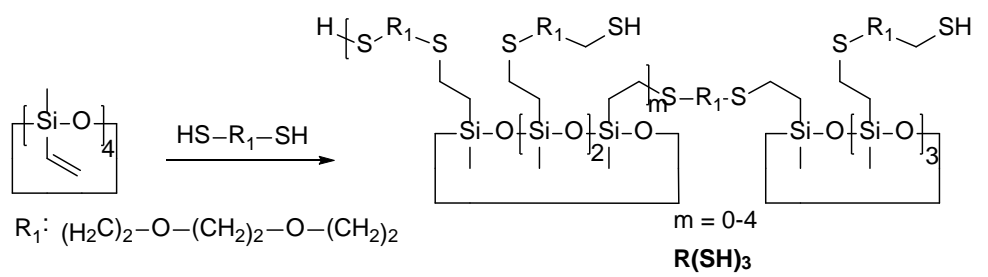


Scheme 1 Synthetic strategy to $\mathbf{P 3}$ and $\mathbf{P 5}$ starting from $\mathrm{V}_{4}$ (a) and to the mercapto-functionalized (oligo)cyclosiloxanes R(SH) cross-linker starting from $\mathrm{V}_{4}$ and 2,2'-(ethylene-dioxy)diethanethiol $\mathrm{R}_{1}(\mathrm{SH})_{2}(\mathrm{~b})$.

In the second step, the vinyl groups were converted to thioethers by the UV-induced thiol-ene addition of ethanethiol mediated by 2,2dimethoxy-1,2-diphenylethan-1-one (DMPA) under mild conditions, i.e. $3 \mathrm{~min}$ UV-irradiation at $0{ }^{\circ} \mathrm{C}$ to give polymer P2. The only side products observed in the thiol-ene reaction were high molecular weight siloxanes, which were most likely formed by an intermolecular vinyl-vinyl coupling during thiol-ene addition. A reduction of P1 concentration in THF and of UV-irradiation time to 3 min eliminated this side reaction. $\mathbf{P 2}$ has both polar side groups and reactive amino end-groups, which we intended to use subsequently for cross-linking into thin films using, for example, the ring-opening of epoxides by amines (Fig. 1). However, this step did not perform as well as we had expected. Therefore, the amino end-groups of $\mathbf{P} \mathbf{2}$ were reacted in situ with allyl isocyanate to afford polymer $\mathbf{P} \mathbf{3}$ that carries allyl endgroups. The synthesis of $\mathbf{P 3}$ was conducted on a $60 \mathrm{~g}$ scale. The allyl groups are linked to siloxane by an urea functionality similarly to urethane links in polyurethane DEs. ${ }^{16}$ The ${ }^{1} \mathrm{H}$ NMR spectrum in Fig. 1 clearly shows that the synthesis of P3 was successful. The absence of vinyl and amino groups and the presence of the thioether and allyl groups in $\mathbf{P 3}$ are clear indications that the reaction took place. According to the ${ }^{1} \mathrm{H}$ NMR end-group analysis, the two different batches of polymers P3 prepared had a $M_{n}=3.5 \mathrm{kDa}$ and a $M_{n}=10 \mathrm{kDa}$, respectively (Fig. S3 - S6).

Parallel to the synthesis of $\mathbf{P 3}$, the synthesis of $\mathbf{P 5}$ that carries thioether side-groups and vinyl end-groups was investigated. The silanol end-terminated poly(methylvinyl)siloxane prepared starting from $\mathbf{V} \mathbf{4}$, was reacted with ethanethiol to give the silanol end-functionalized poly(ethylthioethyl)methylsiloxane P4 (Fig. S7). To introduce the vinyl end-groups a rearrangement reaction of the polysiloxane chains in the presence of vinyldimethyldisiloxane, which occurs under both basic and acid conditions, was planned. Under basic conditions, the obtained product had a rather low molar mass and thus this synthetic path turned to be unattractive (Fig. S8), however, when concentrated $\mathrm{H}_{2} \mathrm{SO}_{4}$ was used, the vinyl-terminated poly(ethyl-2-thioethyl)methylsiloxane was obtained in 76\% yield (Scheme 1a). The GPC elugram revealed two peaks (Fig. S9). The first peak accounted for about $95 \%$ and corresponded to $M_{n}=8.5 \mathrm{kDa}, M_{w}=20 \mathrm{kDa}, P D I=2.4$, while the second one (5\%) was most likely composed of lowmolecular-weight cyclic siloxanes. In the ${ }^{1} \mathrm{H}$ NMR spectrum of P5 the presence of the vinyl end-groups can be clearly seen (Fig. 1). As mentioned above, the allyl and vinyl groups on P3 and P5 will be used subsequently for cross-linking into thin films.

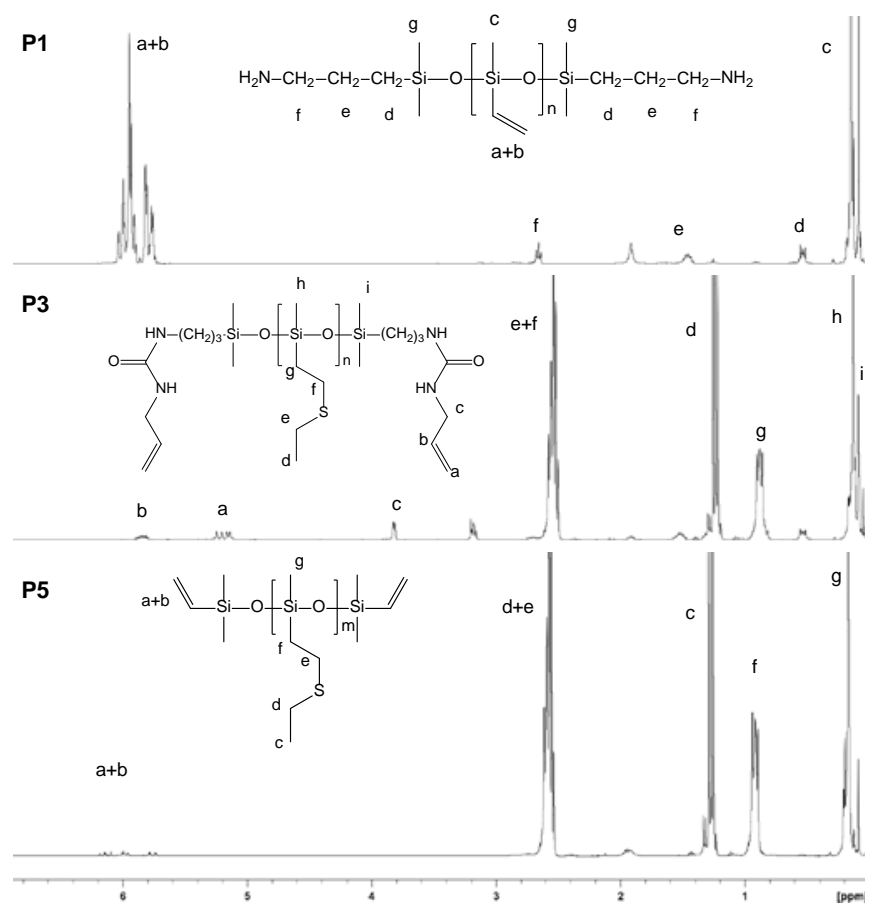

Fig. $1{ }^{1}$ H NMR spectra of P1 (top), P3 (middle), and P5 (bottom).

\subsection{Cross-linking into thin films}

In principle both, the allyl groups of P3 and the vinyl groups of P5 could be used for cross-linking via a hydrosilylation reaction, a reaction commonly used by industry. However, the organosulfur functionalities inactivate the Pt-catalyst and the hydrosilylation is hindered. Hence, the cross-linking of P3 and P5 via thiol-ene addition was investigated (Scheme 2) as this reaction has been successfully used for the synthesis of functional materials. ${ }^{46-48}$ Initially, some commercially available multifunctional thiols were tested, e.g. pentaerythritol tetrakis(3-mercaptopropionate), trimethylolpropane tris(3-mercapto-propionate), and poly(3-mercaptopropyl)methylsiloxane. However, they were poorly miscible with $\mathbf{P 3}$ in the absence of solvent. To overcome this problem, a custom-made oligomeric cross-linker $\mathbf{R}(\mathbf{S H})_{3}$, 
which is a mixture of mercapto-functionalized cyclosiloxanes, was prepared in a one-step synthesis described in Scheme 1b. After removal of the volatiles, $\mathbf{R}(\mathbf{S H})_{3}$ was used without further purification (Fig. S10-S12). For cross-linking of P5, the commercially available poly(3mercaptopropyl)methylsiloxane was found to be suitable, as it is miscible with P5.

As mentioned above, the solvent-free cross-linking of silicone elastomers is a prime advantage for thin film processing by doctor blade technique. This can be achieved with low viscosity formulations. Therefore, the viscosities of P3 $\left(M_{n}=3.5 \mathrm{kDa}\right.$ and $\left.M_{n}=10 \mathrm{kDa}\right)$, of mixtures of $\mathbf{P 3}\left(M_{n}=3.5 \mathrm{kDa}\right)$ with $\mathbf{R}(\mathbf{S H})_{3}$ and $\mathbf{R}^{1}(\mathbf{S H})_{2}$, denoted $\mathbf{P 3}-\mathbf{Y}$, as well as of $\mathbf{P 5}$ and of the cross-linkable mixture $\mathbf{P 5} /$ poly(3mercaptopropyl)methylsiloxane (P5-1) were measured at room temperature and at frequencies between 1 and $10 \mathrm{~Hz}$ (Fig. S13-S21). Their viscosity values $\eta$ at $2 \mathrm{~Hz}$, as well as the one of some silanol-terminated PDMS as internal reference, are summarized in Table 2.

Table 2. Viscosity $\eta$ at $2 \mathrm{~Hz}$ of silanol-terminated PDMSs (OH-PDMS), P3, and cross-linkable mixtures of P3-Y with different weight amounts of $\mathbf{R}(\mathbf{S H})_{3}$ and $\mathbf{R}^{1}(\mathbf{S H})_{2}$ as well as the corresponding $M_{n}$ of the polysiloxanes.

\begin{tabular}{llll}
\hline Entry & $\begin{array}{l}\text { Sample } \\
\left.\mathbf{P n} / \mathbf{R}(\mathbf{S H})_{3} / \mathbf{R}^{\mathbf{1}} \mathbf{( S H}\right)_{\mathbf{2}}\end{array}$ & $M_{n}{ }^{\mathrm{a}}[\mathrm{kDa}]$ & $\begin{array}{l}\eta[\mathrm{Pas}] \text { at } \\
2 \mathrm{~Hz} / 24{ }^{\circ} \mathrm{C}\end{array}$ \\
\hline 1 & $\mathbf{P 3}$ & 10 & 4.6 \\
2 & $\mathbf{P 3}$ & 3.5 & 2.7 \\
3 & $\mathbf{P 3 - 1}$ & 3.5 & 2.3 \\
4 & $\mathbf{P 3 - 2}$ & 3.5 & 1.9 \\
5 & $\mathbf{P 3 - 3}$ & 3.5 & 1.7 \\
6 & $\mathbf{P 3 - 4}$ & 3.5 & 1.6 \\
7 & $\mathbf{P 5}$ & 7 & 2.3 \\
8 & $\mathbf{P 5 - 1}$ & 7 & 1.9 \\
9 & OH-PDMS & 139 & 87.8 \\
10 & OH-PDMS & 63 & 7.7 \\
11 & OH-PDMS & 28 & 0.8 \\
\hline
\end{tabular}

${ }^{\text {a }}$ As determined by ${ }^{1} \mathrm{H}$ NMR.

P3 with a $M_{n}=10 \mathrm{kDa}$ showed a viscosity of $4.6 \mathrm{~Pa}$ s, while P3 with a $M_{n}=3.5 \mathrm{kDa}$ exhibited a viscosity of 2.7 Pa s. The viscosity values of P3-Y, P5, and P5-1 were in the range of 1.6 to $2.3 \mathrm{~Pa} \mathrm{~s}$, values that are comparable to silanol-terminated PDMS with a $M_{n}$ between $28 \mathrm{kDa}$ and $63 \mathrm{kDa}$.

a)

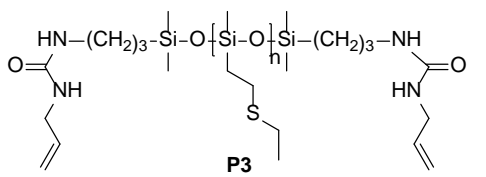

$$
\begin{aligned}
& \underset{\substack{\operatorname{DMPA}_{80} \mathrm{C} \\
\text { a } \mathrm{minh}_{\mathrm{h}} \mathrm{V}}}{\mathrm{R}(\mathrm{SH})_{3}} \\
& \mathrm{R}
\end{aligned}
$$

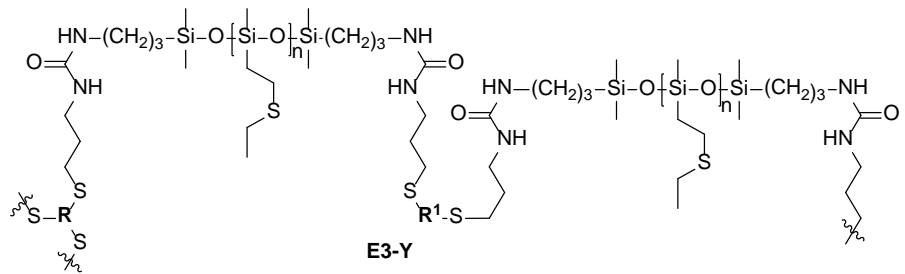<smiles>C=C[Si](C)(C)O[Si](C)(C)O[Si](C)(C)CCSC</smiles>

P5<smiles>C[Si](C)(C)O[Si](C)(C)O[Si](C)(C)C</smiles>

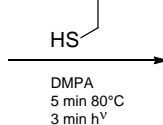

$3 \min \mathrm{n}^{\mathrm{N}}$

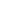

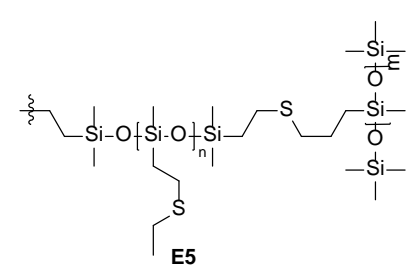

Scheme 2 The synthesis of elastomers E3-Y and E5 in air using a thiol-ene reaction.

The rather high viscosity of $\mathbf{P 3}\left(M_{n}=10 \mathrm{kDa}\right)$ made solvent-free processing in thin films by doctor blade difficult and therefore was not used for further investigations. For all other formulations, the viscosity was sufficiently low to allow formation of defect-free thin films prior to UV-irradiation.

Formation of thin films without defects does not only require a proper selection of the viscosity of the polymers used, but also a careful selection of the substrate on which the films are cast. This is especially important if stacked actuators are envisioned. The formation of the first layer is crucial as this layer will define the quality of the next layers which should be printed. Four substrates were tested: poly(tetrafluoro)ethylene, stainless steel, polyethylene terephthalate, and a poly(vinyl alcohol) (PVA) film coated on a glass substrate. Poly(tetrafluoro)ethylene substrate, which worked nicely with other silicones, did not work in the present case, i.e., the coated film dewetted, a process which is likely favored by the low viscosity of the components used. P3-Y cast on stainless steel and a polyethylene terephthalate substrate gave smooth elastomeric films. However, the peeling off the films from the substrate by hand, which is needed for characterizing the films, was challenging. Please note that this step is not needed when many layers are stacked on top of each other as is 
the case for the production of stacked actuators for which these polymers were designed for. To avoid peeling, a sacrificial layer of poly(vinyl alcohol) (PVA) can be used..$^{49}$ First attempts to process our formulations on PVA were not successful either, because the casted films did not form a uniform surface. This problem was overcome by heating the casted films to $80^{\circ} \mathrm{C}$ for 5 min when smooth films formed which were subsequently cross-linked by UV irradiation. A DuraSeal ${ }^{\mathrm{TM}}$ laboratory stretch film was placed on the silicone films and the PVA substrate was peeled from the glass substrate. This way, any mechanical stress on the silicone films was avoided. Thereafter, the PVA was washed with $\mathrm{H}_{2} \mathrm{O}$. The formed elastomers starting from P3 were denoted as E3-Y, where $\mathrm{Y}$ refers to different compositions (Table 1). The same procedure was applied for the cross-linking of P5 using poly(3-mercaptopropyl)(methyl)siloxane cross-linker to form elastomer $\mathbf{E 5}$ (Scheme 2b).

Since smooth films were achieved only when the substrate was heated to $80^{\circ} \mathrm{C}$, we were concerned about the thermal stability of the precursors used. Therefore the thermal stability of $\mathbf{P 3}, \mathbf{P 5}$, and $\mathbf{R}(\mathbf{S H})_{3}$ was verified in synthetic air $\left(80 \% \mathrm{~N}_{2}\right.$ and $\left.20 \% \mathrm{O}_{2}\right)$. All precursors were stable up to $150{ }^{\circ} \mathrm{C}$, a temperature which is lower than the one used for processing (Fig. S22-S25).

The downside of cross-linking low molecular weight siloxanes, which have a low viscosity, is the high cross-link density. Thus, rather stiff elastomers with low strain at break are formed after cross-linking. To optimize the properties of the elastomers E3-Y, the amount of cross-linker $\mathbf{R}(\mathbf{S H})_{3}$ and chain prolongation reagent $\mathbf{R}_{1}(\mathbf{S H})_{2}$ was tuned. The viscoelastic behavior of E3-Y and E5 was characterized by dynamic mechanical analysis (DMA). The commercially available PDMS Elastosil ${ }^{\circledR}$ Film was used as a reference. ${ }^{50}$ Three independent samples were prepared and analyzed (Fig. S26-S31). The average values of the elastic modulus $E^{\prime}$ and the mechanical loss factor tan $(\delta)$ are depicted in Fig. 2 left. The reproducibility of the cross-linking reaction was studied by performing three cross-linking reactions for each elastomer with the same batch of P3 or P5.

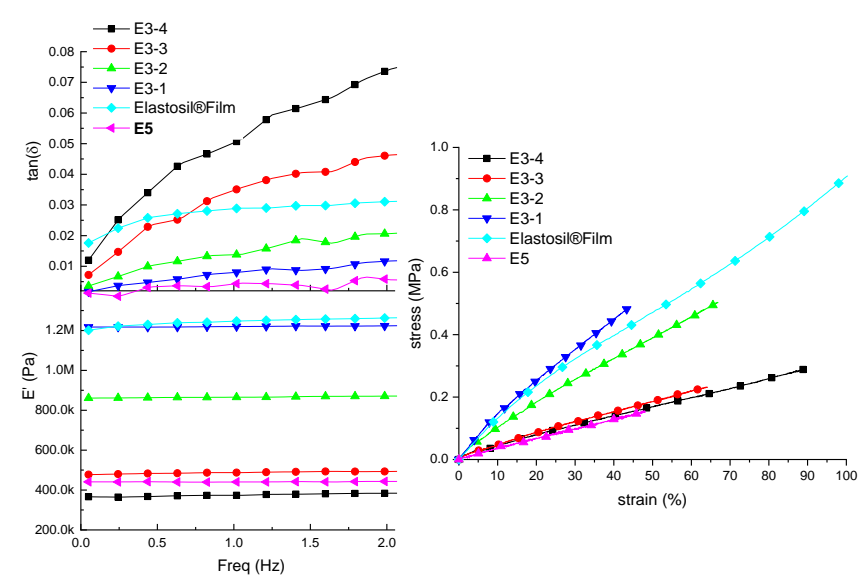

Fig. 2 Dynamic mechanical analysis of E3-Y, E5, and Elastosil ${ }^{\otimes}$ Film conducted at a frequency ranging from $0.05 \mathrm{~Hz}$ to $2 \mathrm{~Hz}$ and at $2 \%$ strain (left) and the stress-strain curves of E3-Y, E5, and Elastosil ${ }^{\circledR}$ Film (right). The curve of the sample with the median value of $s_{\max }$ is given.

E3-1 and E3-2 showed a viscoelastic behavior similar to Elastosil ${ }^{\circledR}$ Film. At $2 \mathrm{~Hz}$ the mechanical loss factors $\tan (\delta)$ of E3-1 and E3-2 were 0.01 and 0.02 , respectively, slightly lower as compared to Elastosil ${ }^{\circledR}$ Film with $\tan (\delta)=0.03$. For E3-3 and E3-4, which contained higher amounts of $\mathbf{R}_{\mathbf{1}}(\mathbf{S H})_{2}$, the mechanical loss factors $\tan (\delta)$ were 0.05 and 0.07 , respectively. Low mechanical losses of silicone elastomers are advantageous since the energy conversion ratio of the actuators increases. ${ }^{15}$ Therefore, a well-balanced trade-off between mechanical loss $\tan (\delta)$ and elastic modulus $E^{\prime}$ as well as maximum strain at break $s_{\max }$ has to be found.

As expected, with increasing the amount of $\mathbf{R}_{1}(\mathbf{S H})_{2}$ in the E3-Y series, a clear softening trend was observed. Thus the storage moduli decreased from 1.22 MPa for E3-1, to 0.5 MPa for E3-3, and to 0.39 MPa for E3-4. E5 had an unexpected low storage modulus without any addition of $\mathbf{R}_{\mathbf{1}}(\mathbf{S H})_{2}$. This might be explained by the higher molecular weight of P5 compared to P3. The viscoelastic behavior of E5 was unusually low for such a soft elastomer. The DMA of E5 recorded every $24 \mathrm{~h}$ over 4 days showed no change in the mechanical properties (Fig. S32). The storage modulus of all materials remained constant over the investigated frequency range.

Figure 2 right depicts the uniaxial stress-strain curves of all elastomers for which the average of three independent tests is given (Fig. S33-S38). According to the tensile tests, the strain at break $s_{\max }$ increases with decreasing elastic modulus $Y_{10 \%}$, i.e. with the amount of $\mathbf{R}_{1}(\mathbf{S H})_{2}$ used. As expected, the cross-linking of low molecular weight siloxanes resulted in elastomers with lower strain at break compared to Elastosil ${ }^{\oplus}$ Film. For example, the stiffest material E3-1 had a strain at break of 47\%, while the softest material E3-4 had a strain at break of $109 \%$. E5 showed also a low strain at break of $46 \%$ and a low Young's modulus of $0.41 \mathrm{MPa}$. While the strain at break values of all materials developed are not high, $s_{\max }$ is not a limiting material parameter in stacked DEAs. ${ }^{44}$ This is particularly the case for low-voltage DEAs for which E3-Y and E5 are designed for. There are several reports on improved $s_{\max }$ for polar silicone elastomers by the addition of fillers, ${ }^{51}$ however, fillers increase the viscosity of the silicone mixtures ${ }^{40}$ and interfere with the thin film processing. Therefore, we avoided using them.

The quality of the elastomeric network was further studied by swelling-extraction experiments in THF (Table 3). They were in most cases in agreement with the DMA measurements. The lowest amount of extractable was found for E3-1, which showed the lowest $\tan (\delta)$ among E3-Y series. In general, the amount of extractable, $m_{\text {ext }}$, was higher compared to Pt-catalyzed cross-linked silicone elastomers. The reason behind this is seen in the degradation products of DMPA, which occurred during post-polymerization modification of P1 and during P3 cross-linking. The DMPA degradation products are non-volatile and thus contributed to the amount of extractable. The softer 
elastomers E3-4 of series E3-Y, with the lower cross-link density, showed the highest amount of extractable species from all elastomers. In case of E5 the $\tan (\delta)$ was even lower as compared to Elastosil ${ }^{\circledR}$ Film, while the amount of extractable is more than four times higher. The reason behind this is seen in the low strain at break of this material, which ruptured into small pieces during our attempts to recover the swollen film and thus did not allow for complete recovery of the material.

Differential scanning calorimetry (DSC) was conducted to investigate the influence of the thioether side groups and the urea linker on both glass transition temperature and melting temperature. E3-Y, as well as E5, did not show any transitions down to $-80{ }^{\circ} \mathrm{C}$, except E3-1 which showed a transition peak at $-61^{\circ} \mathrm{C}$ (Fig. S39-S43). Because of the low transition temperatures, our materials can be in principle used at very low temperatures. The stability of the materials was investigated by TGA, where no degradation below $200{ }^{\circ} \mathrm{C}$ and a maximum of the degradation peak above $335^{\circ} \mathrm{C}$ was observed for all materials (Fig. S44-S48).

Table 3 Storage modulus $E^{\prime}$, mechanical loss factor $\tan (\delta)$ at $2 \mathrm{~Hz}$, the amount of extractable $m_{\text {ext }}$ in $w t \%_{\text {ext }}$, the Young's modulus at $10 \%$ $\left(Y_{10 \%}\right)$ and strain at break $s_{\max }$ of E3-Y, E5, and Elastosil ${ }^{\circledR}$ Film, as well as the molar ratio of chain-prolongation reagent $\mathbf{R}_{\mathbf{1}}(\mathbf{S H})_{2}$ to $\mathbf{P 3}$.

\begin{tabular}{lcccccc}
\hline Entry & $\begin{array}{c}\text { Molar ratio } \\
\mathbf{R}_{\mathbf{1}}(\mathbf{S H})_{\mathbf{2}} / \mathbf{P 3}\end{array}$ & $\begin{array}{c}E^{\prime} \\
{[\mathrm{MPa}]}\end{array}$ & $\tan (\delta)$ & $\begin{array}{c}w t \%_{\text {ext }} \\
{[\%]}\end{array}$ & $\begin{array}{c}Y_{10 \%} \\
{[\mathrm{MPa}]}\end{array}$ & $\begin{array}{c}s_{\max } \\
{[\%]}\end{array}$ \\
\hline E3-1 & 0 & $1.22 \pm 0.02$ & $0.012 \pm 0.001$ & 6.3 & $1.19 \pm 0.09$ & $47 \pm 2$ \\
E3-2 & $1 / 3$ & $0.87 \pm 0.09$ & $0.022 \pm 0.009$ & 13.6 & $0.86 \pm 0.04$ & $79 \pm 7$ \\
E3-3 & $1 / 2$ & $0.50 \pm 0.03$ & $0.046 \pm 0.007$ & 15.2 & $0.42 \pm 0.03$ & $92 \pm 7$ \\
E3-4 & $2 / 3$ & $0.39 \pm 0.03$ & $0.077 \pm 0.003$ & 19.8 & $0.41 \pm 0.05$ & $109 \pm 7$ \\
E5 & - & $0.45 \pm 0.02$ & $0.005 \pm 0.001$ & 17.6 & $0.41 \pm 0.09$ & $46 \pm 5$ \\
Elastosil ${ }^{\circledR}$ Film & - & $1.26 \pm 0.01$ & $0.031 \pm 0.001$ & 3.8 & $1.17 \pm 0.07$ & $486 \pm 34$ \\
\hline
\end{tabular}

\subsection{Dielectric properties}

The dielectric behavior of the developed elastomers at room temperature was investigated by broadband impedance spectroscopy. Relative permittivity $\varepsilon^{\prime}$, dielectric losses $\varepsilon^{\prime \prime}$, the real part of the frequency-dependent conductivity $\left(\sigma^{\prime}=2 \pi v \varepsilon^{\prime \prime}\right)$ and the dielectric losstangent $\tan (\delta)_{e l}=\varepsilon^{\prime \prime} / \varepsilon^{\prime}$ are shown in Fig. 3. The dielectric properties of E3-Y and E5, the liquid oligomers P3 and P5 as well as of cross-linker $\mathbf{R}(\mathbf{S H})_{3}$ are summarized in Table 4 (Fig. S49). The dielectric behavior within the E3-Y series was very similar in the frequency range from $10^{-1}$ $\mathrm{Hz}$ to $10^{6} \mathrm{~Hz}$. At $10^{6} \mathrm{~Hz}$ E3-Y showed values for $\varepsilon^{\prime}$ between 5.7 (E3-4) and 6.2 (E3-1). At a frequency of about $35 \mathrm{kHz}$ a maximum in tan $(\delta)_{e l}$ can be seen, which is likely due to the presence of urea moieties in the polymer backbone. Thus, an increase in permittivity can be observed below this frequency. The absence of this relaxation peak in the dielectric spectrum of $\mathbf{E 5}$ also corroborates that this relaxation peak may be due to urea moiety in E3-Y. The sharp increase in permittivity at a frequency below $10 \mathrm{~Hz}$ observed in E3-Y is due to electrode polarization. Mobile ions are able to accumulate at the electrodes under the influence of an electric field. Elastomer $\mathbf{E 5}$ showed a $\varepsilon^{\prime}=5.5$ at $10^{6} \mathrm{~Hz}$. For E5, the permittivity at low frequency was rather low, which may indicate that the increased ion mobility observed for series E3$\mathbf{Y}$ may be due to urea moieties. Thus, a common feature of E3-Y is the presence of ionic conductivity. This resulted in overall conductivity values in the order of $10^{-10} \mathrm{~S} / \mathrm{cm}$ for E3-Y and in the order of $10^{-12} \mathrm{~S} / \mathrm{cm}$ for E5, whereas Elastosil ${ }^{\oplus}$ Film showed a value of $10^{-15} \mathrm{~S} / \mathrm{cm}$. The increased conductivity had a direct impact on the leakage current at high electric fields, which hindered device operation above $30 \mathrm{~V} / \mu \mathrm{m}$, as shown later for the actuator measurements.

The increased conductivity of materials E3-Y was unexpected since the thioether substituted polysiloxanes reported earlier by our group showed lower conductivity. ${ }^{45}$ To understand the reason behind this increase in conductivity, the dielectric properties of the two components used for the synthesis of $\mathbf{E 3}-\mathbf{Y}, \mathbf{P 3}$, and $\mathbf{R}(\mathbf{S H})_{3}$, were measured. Although the viscosity of P3 was significantly higher as compared to $\mathbf{R}(\mathbf{S H})_{3}$, which should lower ion mobility, the conductivity of $\mathbf{P 3}$ was $2.6 \times 10^{-9} \mathrm{~S} / \mathrm{cm}$, thus higher as compared to the one of $1.7 \times 10^{-10} \mathrm{~S} / \mathrm{cm}$ for $\mathbf{R}(\mathrm{SH})_{3}$. Thus, the increased conductivity at higher frequencies observed for $\mathbf{E} 3-\mathbf{Y}$ is likely due to the urea-functionality of P3. 


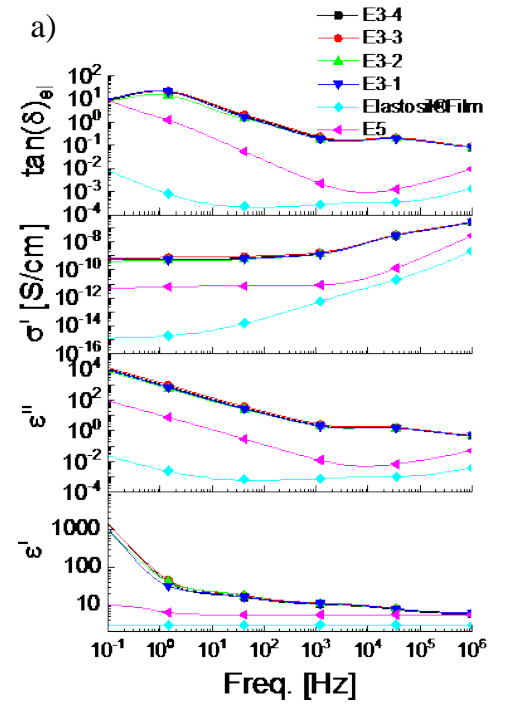

C)

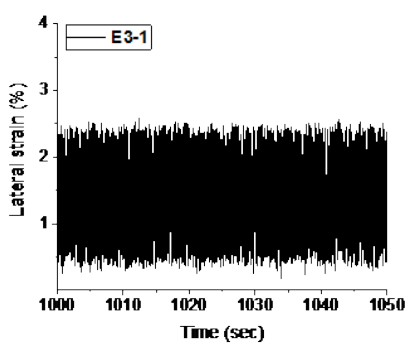

b)

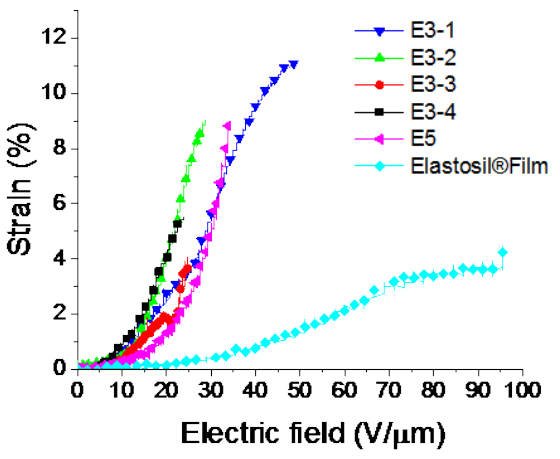

e)
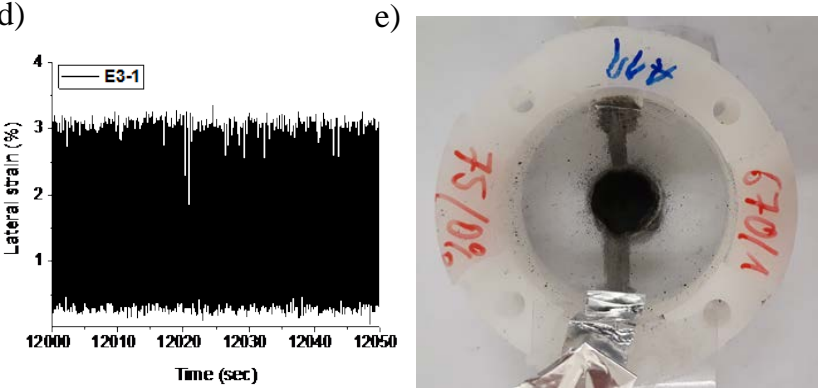

Fig. 3 a) Dielectric properties of E3-Y, E5, and Elastosil ${ }^{\circledR}$ Film. b) Lateral actuation strain of E3-Y, E5, and Elastosil ${ }^{\circledR}$ Film as a function of the applied electric field $U / d$. DEA constructed from a $75 \mu \mathrm{m}$ thin film of E3-1 driven by an electric field of $25 \mathrm{~V} / \mu \mathrm{m}$ at $8 \mathrm{~Hz}$ for $100,000 \mathrm{cycles}$ : c) 400 cycles $/ 50$ seconds of the first operation sweep of 10,000 repetitions. A lateral strain of about $2.5 \%$ was observed. d) 400 cycles/50 seconds of the last operation sweep of 10,000 repetitions. A lateral strain of about $3 \%$ was observed. e) Photograph of the DEA constructed from E3-1 after 100,000 cycles, where it can be observed that some carbon black powder is distributed over the DE inactive part.

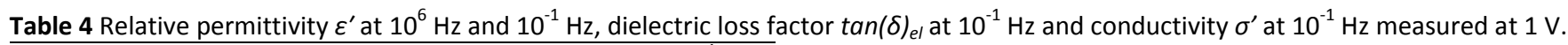

\begin{tabular}{lllll}
\hline Entry & $\begin{array}{l}\varepsilon^{\prime} \text { at } \\
10^{6} \mathrm{~Hz}\end{array}$ & $\begin{array}{l}\varepsilon^{\prime} \text { at } \\
10^{-1} \mathrm{~Hz}\end{array}$ & $\begin{array}{l}\tan (\delta)_{e l} \text { at } \\
10^{-1} \mathrm{~Hz}\end{array}$ & $\begin{array}{l}\sigma^{\prime} \text { at } 10^{-1} \mathrm{~Hz} \\
{[\mathrm{~S} / \mathrm{cm}]}\end{array}$ \\
\hline $\mathbf{R}(\mathrm{SH})_{3}$ & 8.3 & $1.9 \times 10^{2}$ & $1.6 \times 10^{1}$ & $1.7 \times 10^{-10}$ \\
$\mathbf{P 3}$ & 5.9 & $1.2 \times 10^{4}$ & $3.8 \times 10^{0}$ & $2.6 \times 10^{-9}$ \\
E3-1 & 6.2 & $6.6 \times 10^{2}$ & $1.2 \times 10^{1}$ & $3.6 \times 10^{-10}$ \\
E3-2 & 6.1 & $9.2 \times 10^{2}$ & $8.1 \times 10^{0}$ & $4.0 \times 10^{-10}$ \\
E3-3 & 6.0 & $1.4 \times 10^{3}$ & $1.0 \times 10^{1}$ & $7.3 \times 10^{-10}$ \\
E3-4 & 5.7 & $1.5 \times 10^{3}$ & $6.8 \times 10^{0}$ & $5.4 \times 10^{-10}$ \\
E5 & 5.5 & $1.0 \times 10^{1}$ & $8.9 \times 10^{0}$ & $5.1 \times 10^{-12}$ \\
Elastosil ${ }^{\oplus}$ Film & 2.9 & $2.9 \times 10^{0}$ & $7.9 \times 10^{-3}$ & $1.3 \times 10^{-15}$ \\
\hline
\end{tabular}

\subsection{Electromechanical properties}

The dielectric breakdown strength $E_{\max }$ was determined using two different electrode configurations. Rigid metal electrodes with an area of $0.25 \mathrm{~mm}^{2}$ embedded in an epoxy resin, which hindered electromechanical actuation of the dielectric films, and compliant electrodes of carbon black powder with a diameter of $8 \mathrm{~mm}$ applied on free-standing films, like in DEA devices, were used. The voltage was increased by steps of $50 \mathrm{~V}$ or $100 \mathrm{~V}$ up to dielectric breakdown. The dielectric breakdown strength, $E_{\max }$, measured for the unstrained elastomers, E3-Y, varied between $27 \mathrm{~V} / \mu \mathrm{m}$ to $40 \mathrm{~V} / \mu \mathrm{m}$ (Table 5). In case of E5 the dielectric breakdown strength was as high as $E_{\max }=60 \mathrm{~V} / \mu \mathrm{m}$. As expected, $E_{\max }$ was lower for the polar silicone elastomers E3-Y and E5 as compared to Elastosil ${ }^{\circledR}$ Film, which is consistent with the elevated conductivity values found in the impedance spectroscopy.

The $E_{\max }$ values were also measured in actuator configuration using carbon black electrodes and no mechanical prestrain and no air pressure. While the positive effect of prestraining the DEAs on the electromechanical performance has already been extensively described in the literature, prestraining is not compatible with the production of multi-layer DEA for which the materials prepared here were developed. ${ }^{52-55}$ For the actuator construction, the as-prepared DE membrane on the PVA substrate was fixed between two circular plastic 
frames (with an inside diameter of $25 \mathrm{~mm}$ ). Thereafter, the PVA substrate was dissolved in water and then dried. Thus, during the actuator construction, the DE did not experience any mechanical stress. Two compliant electrodes of carbon black with a diameter of $8 \mathrm{~mm}$ were applied on both sides of the DE film. Carbon black powder is an often used electrode material for DEA testing because it does not alter DE properties. However, in this case, the carbon black powder did not adhere sufficiently strong to the silicone elastomer surface (the surface being not sticky enough) and was distributed over the inactive DE surface during measurements. While the dielectric breakdown measurement in actuator configuration is precise, the price for not using prestrain in the DE film and of carbon black electrodes was an inaccurate lateral actuation strain measurement. The values of $E_{\max }$ were calculated with respect to the initial film thickness $d$ of the DE. The voltage was increased in steps of $50 \mathrm{~V}$. The measured dielectric breakdown field $E_{\max }$ of the DEAs indicated a dependence of $E_{\max }$ on the elastic modulus of E3-Y (Table 5, Fig. 3b). The difference between E3-1 with a $E_{\max }=44 \pm 4 \mathrm{~V} / \mu \mathrm{m}$ and E3-4 with a $E_{\max }=24 \pm 4 \mathrm{~V} / \mu \mathrm{m}$ was considerable. As both elastomers have a rather similar chemical composition, the reason for this reduction is attributed to the difference in the elastic modulus. E5 and E3-2 showed very similar dielectric breakdown strength even though the storage modulus of E3-2 was much higher. The reason behind this is seen in the conductivity of E5 which is one order of magnitude lower as compared to E3-2. Elastosil ${ }^{\circledR}$ Film showed a very high dielectric strength of about $95 \mathrm{~V} / \mu \mathrm{m}$.

Table 5 The mean and median value of the dielectric breakdown strength $E_{\max }$ measured with rigid electrodes (electrodes area of 0.25 $\mathrm{mm}^{2}$ ) and the corresponding film thickness. Ten samples were measured. Dielectric breakdown field $E_{\max }$, maximum lateral actuation strain $s_{\text {max }}$, and the lateral actuation strain $s_{a c t}$ at $20 \mathrm{~V} / \mu \mathrm{m}$ of three DEA devices (electrode area of $50 \mathrm{~mm}^{2}$ ) given as mean value with standard deviation.

\begin{tabular}{|c|c|c|c|c|c|c|}
\hline \multirow[t]{2}{*}{ Entry } & \multicolumn{3}{|c|}{ Rigid electrodes $\left(A=0.25 \mathrm{~mm}^{2}\right)$} & \multicolumn{3}{|c|}{ Carbon black electrodes $\left(A=50 \mathrm{~mm}^{2}\right)$} \\
\hline & $\begin{array}{c}\text { Median } E_{\text {max }} \\
{[\mathrm{V} / \mu \mathrm{m}]}\end{array}$ & $\begin{array}{c}\text { Mean } E_{\max } \\
{[\mathrm{V} / \mu \mathrm{m}]}\end{array}$ & $\begin{array}{l}\text { thickness } d \\
{[\mu \mathrm{m}]}\end{array}$ & $\begin{array}{c}E_{\max } \\
{[\mathrm{V} / \mu \mathrm{m}]}\end{array}$ & $\begin{array}{l}s_{\max } \\
{[\%]}\end{array}$ & $\begin{array}{c}s_{a c t} @ 20 \\
V / \mu \mathrm{m} \\
{[\%]}\end{array}$ \\
\hline E3-1 & $33 \pm 3$ & $34 \pm 3$ & $71 \pm 9$ & $44 \pm 4$ & $10 \pm 3$ & $2 \pm 1$ \\
\hline E3-2 & $40 \pm 6$ & $40 \pm 6$ & $72 \pm 6$ & $31 \pm 3$ & $8 \pm 2$ & $4 \pm 2$ \\
\hline E3-3 & $28 \pm 3$ & $27 \pm 3$ & $74 \pm 10$ & $26 \pm 2$ & $4 \pm 1$ & $2 \pm 1$ \\
\hline E3-4 & $28 \pm 1$ & $28 \pm 2$ & $71 \pm 9$ & $24 \pm 4$ & $5 \pm 1$ & $4 \pm 1$ \\
\hline E5 & $60 \pm 11$ & $60 \pm 11$ & $94 \pm 5$ & $30 \pm 4$ & $7 \pm 3$ & $2 \pm 1$ \\
\hline Elastosil ${ }^{\circledR}$ Film & $72 \pm 15$ & $72 \pm 15$ & $50 \pm 0$ & $95 \pm 3$ & $4 \pm 1$ & $0 \pm 0$ \\
\hline
\end{tabular}

The lateral actuation strains of different elastomers are depicted in Fig. 3b, but could not accurately be determined by our method because out of the plane actuation occurred due to the lack of prestrain in the actuators. The curves are based on the average lateral strains in $x$ - and $y$-direction of the median DEA's actuation of 3 independent DEA devices (Fig. S50-55, Table 5). The positive effect of high permittivity and of a low elastic modulus can be clearly observed. In case of E3-1 $\left(\varepsilon^{\prime}=6.2\right)$ the high actuation strain at low electric fields is rather unexpected as the elastic modulus measured by DMA and tensile tests were in the same range as Elastosil ${ }^{\circledR}$ Film $\left(\varepsilon^{\prime}=2.9\right)$. For example, at $30 \mathrm{~V} / \mu \mathrm{m}$ an actuation strain of $6 \%$ was measured for E3-1, whereas Elastosil ${ }^{\otimes}$ Film gave a significantly lower actuation of only $0.5 \%$. E5 gave a lateral actuation strain of $7 \%$ at $30 \mathrm{~V} / \mu \mathrm{m}$. Thus, the high strains at low electric fields must be related to the high permittivity of E3-1. Additionally, the internal stress in E3-1, which may be introduced during the cross-linking reaction and may be preserved in the DEA devices as well as the presence of polar urea groups incorporated into the polymer backbone may also play a role.

The electromechanical response speed and reliability of the polar silicone elastomers were characterized by cyclic DEA measurements in the frequency range of $1 \mathrm{~Hz}$ to $8 \mathrm{~Hz}$. Three DEA devices were constructed and characterized for each elastomer. Table 6 summarizes the lateral actuation in cyclic tests of the DEA samples at frequencies between $1 \mathrm{~Hz}$ and $8 \mathrm{~Hz}$. Because the films were not prestrained, the outof-plane actuation was considerable. Nonetheless, the tests are meaningful with respect to the response speed and reliability of the DEA device. For each frequency 100 actuation cycles were conducted. The electric fields selected for these investigations were below the measured $E_{\max }$ values. Thus, E3-1 was operated at $30 \mathrm{~V} / \mu \mathrm{m}, \mathrm{E3}-2 / 3$ and E5 at $25 \mathrm{~V} / \mu \mathrm{m}, \mathrm{E3}-4$ at $20 \mathrm{~V} / \mu \mathrm{m}$, and Elastosil ${ }^{\circledR}$ Film at $80 \mathrm{~V} / \mu \mathrm{m}$. At electric fields below $30 \mathrm{~V} / \mu \mathrm{m}$ the actuation strain of Elastosil ${ }^{\oplus}$ Film was too small to be measured. Although the actuation strain of all samples was similar, the electric field was reduced from $30 \mathrm{~V} / \mu \mathrm{m}$ for E3-1 to $20 \mathrm{~V} / \mu \mathrm{m}$ for E3-4. At the above mentioned electric fields, the lateral actuation strain was about 2-4\% for E3-2/3/4, while for Elastosil ${ }^{\circledR}$ Film, E3-1, and E5 it was about 4-6\%. For E3-Y and E5 up to 8 Hz no significant dependence of strain and frequency was observed (Fig. S56-S59).

Table 6 Average actuation in cyclic tests over 100 cycles at $1-8 \mathrm{~Hz}$ at an electric field of $80 \mathrm{~V} / \mu \mathrm{m}$ of Elastosil ${ }^{\oplus} \mathrm{Film}, 30 \mathrm{~V} / \mu \mathrm{m}$ of E3-1, 25 $\mathrm{V} / \mu \mathrm{m}$ of E3-2/E3-3 and E5, and $20 \mathrm{~V} / \mu \mathrm{m}$ of E3-4.

\begin{tabular}{ccccc}
\hline Entry & Strain@ & Strain@ & Strain@ & Strain@ \\
& $1 \mathrm{~Hz}[\%]$ & $2 \mathrm{~Hz}[\%]$ & $4 \mathrm{~Hz}[\%]$ & $8 \mathrm{~Hz}[\%]$ \\
\hline E3-1 & 6 & 4 & 4 & 6 \\
E3-2 & 2 & 3 & 2 & 3 \\
E3-3 & 2 & 3 & 3 & 2 \\
E3-4 & 3 & 3 & 3 & 2 \\
E5 & 6 & 6 & 5 & 4 \\
Elastosil ${ }^{\circledR}$ Film & 3 & 3 & 3 & 2 \\
\hline
\end{tabular}


Notably, one DEA constructed from E3-4 and E3-2 and two DEAs constructed from E3-3 suffered dielectric breakdown during the cyclic tests. In the case of E3-4 and E3-3 the mechanical stability of the elastomeric thin films might have been too low (see DMA). In addition, the applied electric fields might have been too close to the dielectric breakdown $E_{\max }$ of the materials. The defective DE samples showed clear signs of morphological changes on the entire electrode surface. In case of Elastosil ${ }^{\circledR}$ Film the electric breakdown could be exactly located on the surface of the elastic film.

The elevated conductivity of E3-Y has already been identified by broadband impedance spectroscopy at $1 \mathrm{~V}$. Thus, the DC leakage current $i_{\text {leak }}$ of the DEA device was measured. The values are summarized in Table 7. The leakage current led to the dissipation of electrical energy in the DEA. This might be one important aspect of the electrical breakdown of the polar silicone elastomers. The dissipated electrical power is proportional to the leakage current and the applied voltage. This implies a dependence of dissipated electrical power on the thickness $d$ of the DE.

Table 7 Leakage current $i_{\text {leak }}$ (DC) of the DEA test device at a given electric field $U / d$ with the corresponding dissipated electrical power.

\begin{tabular}{|c|c|c|c|c|}
\hline Entry & $\begin{array}{c}i_{\text {leak }} \\
{[\mu \mathrm{A}]^{\mathrm{a}}}\end{array}$ & $\begin{array}{c}U / d \\
{[\mathrm{~V} / \mu \mathrm{m}]}\end{array}$ & $\begin{array}{c}\text { Dissipated power } \\
{[\mathrm{mW}]}\end{array}$ & 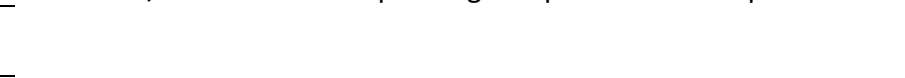 \\
\hline E3-1 & 10 & 10 & $7.5^{c}$ & \\
\hline E3-2 & 8 & 10 & $6.8^{d}$ & \\
\hline E3-3 & 10 & 10 & $9.0^{\mathrm{e}}$ & \\
\hline E3-4 & 10 & 10 & $10.0^{f}$ & \\
\hline E5 & $<3$ & 25 & $<6.2^{\mathrm{g}}$ & \\
\hline Elastosil ${ }^{\circledR}$ Film & $<1$ & 80 & $<3.6^{\mathrm{h}}$ & \\
\hline
\end{tabular}

In the case of E3-Y the leakage current was considerable even at low electric fields. For E5 the leakage current below $25 \mathrm{~V} / \mu \mathrm{m}$ was lower than $3 \mu \mathrm{A}$. We have recently reported a thioether functionalized polar silicone elastomer that has a negligible leakage current below an electric field of $27 \mathrm{~V} / \mu \mathrm{m} .{ }^{45}$ The polar siloxane was a poly(propylthioethyl)methylsiloxane cross-linked by a tin-catalyzed condensation reaction with $(\mathrm{EtO})_{3} \mathrm{Si}\left(\mathrm{CH}_{2}\right)_{3} \mathrm{Cl}$. Since the dielectric properties of $\mathbf{R}(\mathrm{SH})_{3}$ are comparable to that of $(\mathrm{EtO})_{3} \mathrm{Si}\left(\mathrm{CH}_{2}\right)_{3} \mathrm{Cl}$, ${ }^{44}$ it is very likely that the presence of urea functionality in E3-Y is responsible for the increased leakage current. With respect to the urea functionality the structural similarity to the urethane group might lead to the question whether polyurethane elastomers, in general, might suffer from elevated conductivity as well. However, to the best of our knowledge, none of the reported polyurethane DEs have been tested for leakage current in electromechanical devices. ${ }^{16}$

Finally, the maximum lifetime of E3-Y and E5 in DEAs was determined by cyclic measurements at low electric fields (Fig. S60-S64). The applied electric field with a frequency of $8 \mathrm{~Hz}$ was further reduced to prevent premature electric breakdown due to excessive heat. No mechanical prestrain was applied and carbon black powder was used as an electrode material and renewed after 10000 cycles if necessary. During the lifetime measurement, the carbon black was distributed over the surface of the DE. This made the actuation strain measurement by the digital camera inaccurate. Interestingly, it was observed that the adhesion of the carbon black powder onto the surface of the DE was better for E3-4/E3-3 than for E3-1, which could be rationalized by the E3-4 stickiness. This allowed continuous actuation of up to 30,000 cycles for actuators constructed from E3-3 and then more carbon black powder has to be applied. The DEA lifetime performance of E3-1 was unexpectedly high with 100,000 cycles at $25 \mathrm{~V} / \mu \mathrm{m}(10 \times 10,000 \mathrm{cycles}$ at $8 \mathrm{~Hz})$. Fig. 3 shows an image section of 50 seconds of the first (Fig. 3c) and the last operation sweep (Fig. 3d). In case of E3-1 neither mechanical fatigue nor excessive heat could limit the DEA lifetime. The lateral strain was about 2-3\%. However, the carbon black powder was distributed over the inactive DE surface, which rendered exact strain measurements impossible (Fig. 3e). For E3-2 and E3-3 the DEA lifetime was 70,000 and 90,000 cycles at $29 \mathrm{~V} / \mu \mathrm{m}$ and $25 \mathrm{~V} / \mu \mathrm{m}$. E3-4 could only be operated for 10,000 cycles at $15 \mathrm{~V} / \mu \mathrm{m}$. The actuation strain of E3-4 was not constant though. Signs of excessive heat and material fatigue of the free-standing elastomeric film in the DEA device were obvious. This can be attributed to both, the increased mechanical loss factor, observed by DMA, in combination with the high leakage current. From all materials, E5 showed the best DEA lifetime performance with 180,000 cycles at $25 \mathrm{~V} / \mu \mathrm{m}$ at $8 \mathrm{~Hz}$ (Table 8). The reason behind this can be seen in the very low viscoelastic losses and low leakage current.

Cyclic tests for DEAs constructed from regular polydimethylsiloxane elastomers show that actuators can survive millions of cycles, but the lifetime of DEAs is significantly decreased with increasing the humidity level. ${ }^{56}$ Unfortunately, the lifetime tests of actuators constructed from novel dielectric elastomers are rare, ${ }^{44,57-61}$ for most materials such investigations were not reported. ${ }^{62-66}$ Furthermore, investigations on how high dielectric permittivity materials behave in different humidity environment are also needed.

Table 8. The lifetime of the DEA operated at $8 \mathrm{~Hz}$ at a given electric field $U / d$.

\begin{tabular}{lcc}
\hline Entry & $\begin{array}{c}U / d \\
{[\mathrm{~V} / \mu \mathrm{m}]}\end{array}$ & Operation cycles \\
\hline E3-1 & 25 & $100,000^{\mathrm{a}}$ \\
E3-2 & 29 & $70,000^{\mathrm{b}}$ \\
E3-3 & 25 & $90,000^{\mathrm{b}}$ \\
E3-4 & 15 & $10,000^{\mathrm{b}}$ \\
E5 & 25 & $180,000^{\mathrm{a}}$ \\
\hline
\end{tabular}

${ }^{a}$ The actuators are still functioning; ${ }^{b}$ the actuators are damaged. 


\section{Conclusions}

A simple and cost-efficient synthesis of low-viscosity high permittivity silicones, which can be processed without solvents and cross-linked on-demand within few minutes by exposure to the UV-light, is developed. The strategy of end-group functionalization proves beneficial with respect to mechanical losses. Additionally, the mechanical properties of the elastomers can be tuned by the amount of cross-linker and chain prolongation used. The dielectric and mechanical properties of the DE thin films are compared with those of Elastosil ${ }^{\circledR}$ Film. The permittivity of the elastomer developed here is enhanced by a factor of 2 , but the strain at break is lower as compared to Elastosil ${ }^{\circledR}$ Film. However, this property does not affect the DEA performance at low electric fields. Due to the increased permittivity and low elastic modulus, enhanced DEA performance at electric fields of only 20-30 V/ $\mu \mathrm{m}$ is realized. A reduction of the elastic modulus by chain-prolongation is possible, but the mechanical losses are increased and the lifetime in DEAs is reduced. In addition, the urea functionality increases the conductivity of the silicone elastomers. The lifetime of 100,000 actuation cycles supports the mechanical stability of the polar silicone elastomers in the unprestrained DEA operated at $25 \mathrm{~V} / \mu \mathrm{m}$. Another silicone elastomer $\left(\varepsilon^{\prime}=5.5\right)$ that has no urea moieties and shows negligible leakage current at electric fields below $25 \mathrm{~V} / \mu \mathrm{m}$ is also developed. Its electromechanical stability is supported by the lifetime measurements of 180,000 cycles at $25 \mathrm{~V} / \mu \mathrm{m}$. The materials developed here address most issues that limit the technological relevance of high permittivity silicone elastomers for actuator applications.

\section{Conflicts of interest}

There are no conflicts to declare.

\section{Acknowledgements}

We gratefully acknowledge the Swiss National Science Foundation (IZERZO_142215 and 200020_172693) and Swiss Federal Laboratories for Materials Science and Technology (Empa, Dübendorf) for financial support. We also acknowledge B. Fischer and T. Kuenniger (both Empa) for their support with GPC, TGA, and DMA measurements, Dr. G. Kovacs (Empa) for providing us access to the electromechanical tests, L. Düring (CT Systems) for useful discussions and his continuous technical support, C. Walder for his support with the rheometer, and D. Rentsch for useful discussions.

\section{References}

1. R. Pelrine, R. Kornbluh, Q. Pei and J. Joseph, Science, 2000, 287, 836.

2 R. Pelrine, R. Kornbluh, J. Joseph, R. Heydt, Q. Pei and S. Chiba, Mater. Sci. Eng. C 2000, 11, 89.

3 T. A. Gisby, B. M. Obrien and I. A. Anderson, Appl. Phys. Lett. 2013, 102, 193703.

4 M. Aschwanden and A. Stemmer, Opt. Lett. 2006, 31, 2610.

5 L. Düring and G. Kovacs (Empa), WO 2009/135328 A2, 2009.

6 D. M. Opris, Adv. Mater. 2018, 30, 1703678.

7 R. Kaltseis, C. Keplinger, S. J. Adrian Koh, R. Baumgartner, Y. F. Goh, W. H. Ng, A. Kogler, A. Tröls, C. C. Foo, Z. Suo and S. Bauer, RSC Adv. 2014, 4, 27905.

8 Y. Qiu, E. Zhang, R. Plamthottam and Q. Pei, Acc. Chem. Res. 2019, 52, 316.

9 G. Gallone, F. Galantini and F. Carpi, Polym. Int. 2010, 59, 400.

10 M. A. Brook, Silicones, In Silicon in Organic, Organometallic and Polymer Chemsitry; Wiley: New York, 2000; pp 256-308.

11 L. Maffli, S. Rosset, M. Ghilardi, F. Carpi and H. Shea, Adv. Funct. Mater. 2015, 25, 1656.

12 C. Jordi, A. Schmidt, G. Kovacs, S. Michel and P. Ermanni, Smart Mater. Struct. 2011, 20, 075003.

13 H. Haus, M. Matysek, H. Mößinger and H. F. Schlaak, Smart Mater. Struct. 2013, 22, 104009.

14 P. Brochu and Q. Pei, Macromol. Rapid Commun. 2010, 31, 10.

15 S. Michel, X. Q. Zhang, M. Wissler, C. Löwe and G. Kovacs, Polym. Int. 2010, 59, 391.

16 J. Biggs, K. Danielmeier, J. Hitzbleck, J. Krause, T. Kridl, S. Nowak, E. Orselli, X. Quan, D. Schapeler, W. Sutherland and J. Wagner, Angew. Chem. Int. Ed. 2013, 52, 9409.

17 H. Stoyanov, P. Brochu, X. Niu, C. Lai, S. Yun and Q. Pei, RSC Adv. 2013, 3, 2272.

18 C. Racles, M. Alexandru, A. Bele, V. E. Musteata, M. Cazacu and D. M. Opris, RSC Adv. 2014, 4, 37620.

19 A. Maziz, C. Plesse, C. Soyer, C. Chevrot, D. Teyssié, E. Cattan and F. Vidal, Adv. Funct. Mater. 2014, 24, 4851.

20 J. D. Madden, D. Rinderknecht, P. A. Anquetil and I. W. Hunter, Sensors Actuators, A Phys. 2007, 133, 210.

21 Y. Li, J. Ho, J. Wang, Z. M. Li, G. J. Zhong and L. Zhu, ACS Appl. Mater. Interfaces 2016, 8, 455.

22 T. Töpper, S. Lörcher, H. Deyhle, B. Osmani, V. Leung, T. Pfohl and B. Müller, Adv. Electron. Mater. 2017, 3, 1700073.

23 R. Shankar, T. K. Ghosh and R. J. Spontak, Adv. Mater. 2007, 19, 2218.

24 F. Galantini, F. Carpi and G. Gallone, Smart Mater. Struct. 2013, 22, 104020.

25 T. Hirai, H. Sadatoh, T. Ueda, T. Kasazaki, Y. Kurita, M. Hirai and S. Hayashi, Die Angew. Makromol. Chem. 1996, $240,221$.

26 F. M. Weiss, F. B. Madsen, T. Töpper, B. Osmani, V. Leung and B. Müller, Mater. Des. 2016, 105, 106. 
27 D. McCoul, S. Rosset, S. Schlatter and H. Shea, Smart Mater. Struct. 2017, 26, 125022.

28 G. Kovacs, L. Duering, S. Michel and G. Terrasi, Sens. Actuators, A 2009, 155, 299.

29 F. Carpi, C. Salaris and D. De Rossi, Smart Mater. Struct. 2007, 16, S300.

30 D. Yang, S. Huang, M. Ruan, S. Li, Y. Wu, W. Guo and L. Zhang, Compos. Sci. Technol. 2018, $155,160$.

31 G. Gallone, F. Carpi, D. De Rossi, G. Levita and A. Marchetti, Mater. Sci. Eng. C 2007, $27,110$.

32 P. Mazurek, S. Hvilsted and A. L. Skov, Polymer. 2016, 87, 1.

33 C. Niu, X. Dong and M. Qi, ACS Appl. Mater. Interfaces 2015, 7, 24855.

34 D. M. Opris, M. Molberg, C. Walder, Y. S. Ko, B. Fischer and F. A. Nüesch, Adv. Funct. Mater. $2011,21,3531$.

35 F. Carpi, G. Gallone, F. Galantini and D. De Rossi, Adv. Funct. Mater. 2008, 18, 235.

36 C. Racles, V. Cozan, A. Bele and M. Dascalu, Des. Monomers Polym. 2016, 5551, 1.

37 S. J. Dünki, Y. S. Ko, F. A. Nueesch and D. M. Opris, Adv. Funct. Mater. 2015, 25, 2467.

38 M. Stepp, F. Achenbach and A. Koellenbacher (Wacker Chemie AG), WO 2015/121261 A1, 2015.

39 D. Opris, M. Dascalu, S. Dünki, J. E. Quinsaat and Y. S. Ko, RSC Adv. 2015, 5, 104516.

40 B. Kussmaul, S. Risse, G. Kofod, R. Waché, M. Wegener, D. N. McCarthy, H. Krüger and R. Gerhard, Adv. Funct. Mater. $2011,21,4589$.

41 F. B. Madsen, L. Yu, A. E. Daugaard, S. Hvilsted and A. L. Skov, RSC Adv. 2015, 5, 10254.

42 S. J. Dünki, Y. S. Ko, F. A. Nüesch and D. M. Opris, Adv. Funct. Mater. 2015, 25, 2467.

43 S. Dünki, F. Nueesch and D. Opris, J. Mater. Chem. C 2016, 10545.

44. Y. Sheima, P. Caspari, D. M. Opris, Macrol. Rapid Commun. 2019, 1900205.

45 P. Caspari, S. J. Dünki, F. Nueesch and D. Opris, J. Mater. Chem. C 2018, 6, 2043.

46 L. Xue, Y. Zhang, Y. Zuo, S. Diao, J. Zhang and S. Feng, Mater. Lett. 2013, 106, 425.

47 K. Goswami, A. L. Skov and A. E. Daugaard, Chem. Eur. J. 2014, 20, 9230.

48 C. Ellingford, R. Zhang, A. M. Wemyss, C. Bowen, T. McNally, Ł. Figiel and C. Wan, ACS Appl. Mater. Interfaces $2018,10,38438$.

49 A. Komp, J. Rühe and H. Finkelmann, Macromol. Rapid Commun. 2005, 26, 813.

50 F. Förster-Zuegel, T. Grotepaß and H. F. Schlaak, SPIE Proc. 2015, 9430, 94300D.

51 A. Bele, M. Dascalu, C. Tugui, M. lacob, C. Racles, L. Sacarescu and M. Cazacu, Mater. Des. $2016,106,454$.

52 J. Huang, S. Shian, R. M. Diebold, Z. Suo and D. R. Clarke, Appl. Phys. Lett. 2012, 101, 122905.

53 A. Tröls, A. Kogler, R. Baumgartner, R. Kaltseis, C. Keplinger, R. Schwödiauer, I. Graz and S. Bauer, Smart Mater. Struct. 2013, 22, 104012

54 F. Carpi, I. Anderson, S. Bauer, G. Frediani, G. Gallone, M. Gei, C. Graaf, C. Jean-Mistral, W. Kaal, G. Kofod, M. Kollosche, R. Kornbluh, B. Lassen, M. Matysek, S. Michel, S. Nowak, B. O’Brien, Q. Pei, R. Pelrine, B. Rechenbach, S. Rosset and H. Shea, Smart Mater. Struct. 2015, 24, 105025.

55 M. Matysek, P. Lotz, K. Flittner and H. F. Schlaak, Proc. SPIE 2008, 6927, 692722.

56 C. A. de Saint-Aubin, S. Rosset, S. Schlatter and H. Shea, Smart Mater. Struct. 2018, $27,074002$.

57 H. Stoyanov, P. Brochu, X. Niu, C. Lai, S. Yun and Q. Pei, RSC Adv., 2013, 3, 2272-2278.

58 P. Brochu, H. Stoyanov, X. Niu and Q. Pei, Smart Mater. Struct. 2013, 22, 055022.

59 M. Dascalu, S. J. Dünki, J.-E. Q. Quinsaat, Y. S. Ko, F. A. Nüesch and D. M. Opris, RSC Adv., 2015, 5, 104516-104523.

60 D. M. Opris, M. Molberg, C. Walder, Y. S. Ko, B. Fischer and F. A. Nüesch, Adv. Funct. Mater., 2011, 21, 3531-3539.

61 M. Duduta, R. J. Wood and D. R. Clarke, Adv. Mater. 2016, 28, 8058.

62 H. Sun, X. Liu, B. Yu, Z. Feng, N. Ning, G.-H. Hu, M. Tian and L. Zhang, Polym.Chem., 2019, 10, 633-645.

63 C. Tugui, S. Vlad, M. Iacob, C. D. Varganici, L. Pricop and M. Cazacu, Polym.Chem., 2016, 7, $2709-2719$.

64 H. Sun, C. Jiang, N. Ning, L. Zhang, M. Tian and S. Yuan, Polym.Chem., 2016, 7,4072-4080.

65 K. Y. Cho, A. Cho, H.-J. Kim, S.-H. Park, C. M. Koo, Y. J. Kwark, H. G. Yoon, S. S. Hwang and K.-Y. Baek, Polym.Chem., 2016, 7, 7391-7399. 66 L. Zhang, D. Wang, P. Hu, J.-W. Zha, F. You, S.-T. Li and Z.-M. Dang, J. Mater. Chem. C, 2015, 3, 4883-4889. 